\title{
1 Microbial community adaptation influences long-chain fatty acid conversion 2 during anaerobic codigestion of fats, oils, and grease with municipal sludge
}

3
Ryan M. Ziels $^{\mathrm{a}^{*}}$, Anna Karlsson ${ }^{\mathrm{b}}$, David A.C. Beck ${ }^{\mathrm{c}}$, Jörgen Ejlertsson ${ }^{\mathrm{b}}$, Sepehr Shakeri Yekta ${ }^{\mathrm{d}}$, Annika Bjorn $^{\text {d }}$, H. David Stensel ${ }^{\mathrm{a}}$, Bo H. Svensson ${ }^{\mathrm{d}}$

${ }^{a}$ Civil and Environmental Engineering, University of Washington, WA

${ }^{\mathrm{b}}$ Scandinavian Biogas Fuels AB, Stockholm, Sweden

${ }^{c}$ eScience Institute, University of Washington, WA

${ }^{\mathrm{d}}$ Department of Thematic Studies - Environmental Change, Linköping University, Sweden

* Corresponding author (email: ziels@uw.edu)

** Corresponding author (email: bo.svensson@liu.se)

Keywords: Anaerobic digestion; fats, oils, grease (FOG); long-chain fatty acids (LCFA); biogas; syntrophy; methanogen 


\section{Abstract:}

24 Codigesting fats, oils, and greases with municipal wastewater sludge can greatly improve

25 biomethane recovery at wastewater treatment facilities. Process loading rates of fats, oils, and

26 greases have been previously tested with little knowledge of the digester microbial community

27 structure, and high transient fat loadings have led to long chain fatty acid (LCFA) accumulation

28 and digester upsets. This study utilized recently-developed quantitative PCR assays for

29 syntrophic LCFA-degrading bacteria along with $16 \mathrm{~S}$ amplicon sequencing to relate changes in

30 microbial community structure to LCFA accumulation during transient loading increases to an

31 anaerobic codigester receiving waste restaurant oil and municipal wastewater sludge. The 16S

32 rRNA gene concentration of the syntrophic $\beta$-oxidizing genus Syntrophomonas increased to

$33 \sim 15 \%$ of the Bacteria community in the codigester, but stayed below $3 \%$ in the control digester

34 that was fed only wastewater sludge. Methanosaeta and Methanospirillum were the dominant

35 methanogenic genera enriched in the codigester, and together comprised over $80 \%$ of the

36 Archaea community by the end of the experimental period. Constrained ordination showed that

37 changes in the codigester Bacteria and Archaea community structures were related to measures

38 of digester performance. Notably, the codigester LCFA concentration was positively correlated

39 to the specific loading rate of waste oil normalized to the Syntrophomonas 16S rRNA

40 concentration in the codigester. Specific loading rates of 0 to $1.5 \times 10^{-12} \mathrm{~g}$ VS oil/ $16 \mathrm{~S}$ gene copies-

41 day resulted in LCFA concentrations below $30 \mathrm{mg} / \mathrm{g}$ TS, whereas LCFA accumulated up to 104

$42 \mathrm{mg} / \mathrm{g}$ TS at higher transient loading rates. Based on the community-dependent loading

43 limitations found, enhanced biomethane production from high loadings of fats, oils and greases

44 can be achieved by promoting a higher biomass of slow-growing syntrophic consortia, such as

45 with longer digester solids retention times. This work also demonstrates the potential for 
46 controlling the loading rate of fats, oils, and greases based on the analysis of the codigester

47 community structure, such as with quantitative PCR measurements of syntrophic LCFA48 degrading bacteria abundance. 


\section{INTRODUCTION}

51 Anaerobic digestion is commonly used at municipal wastewater treatment plants (WWTPs) to

52 process waste sludge and recover renewable energy as biomethane. Fats, oils, and greases (FOG)

53 are desirable substrates for enhancing biomethane recovery through codigestion because they

54 have a methane yield potential per g VS that is $250 \%$ to $350 \%$ greater than the wastewater sludge

55 typically fed to municipal digesters (Davidsson et al., 2008; Girault et al., 2012; Luostarinen et 56 al., 2009). Reported increases in digester methane production from $140 \%$ to $620 \%$ during FOG

57 codigestion with wastewater sludge (Wan et al., 2011; Wang et al., 2013) have demonstrated the

58 potential to significantly improve economics and reduce energy footprints of municipal WWTPs 59 with FOG codigestion.

61 When fats and oils are added to the anaerobic digestion process, they are rapidly hydrolyzed into 62 their major constituents of glycerol and long-chain fatty acids (LCFA) (Hanaki et al., 1981). 63 After lipid hydrolysis, most of the energy content resides in LCFA, which can comprise over

$6490 \%$ of the chemical oxygen demand of the original lipid molecule (Sousa et al., 2009). The 65 formation of methane from LCFA involves a syntrophic partnership of proton-reducing 66 acetogenic bacteria, which utilize the $\beta$-oxidation pathway to convert LCFA into acetate and 67 formate/hydrogen, along with aceticlastic and hydrogenotrophic methanogenic archaea (Schink, 68 1997; Sousa et al., 2009; Weng and Jeris, 1976). All of the isolated bacterial species known to $\beta$ 69 oxidize LCFA syntrophically belong to two families, Syntrophomonadaceae and Syntrophaceae 70 (Hatamoto et al., 2007; Jackson et al., 1999; McInerney, 1992; Sousa et al., 2007b; Wu et al., 71 2007). Generally, the conversion of LCFA into methane is considered the rate-limiting step for 
72 lipid degradation in anaerobic digesters (Angelidaki \& Ahring, 1992; Cirne et al., 2007; Hanaki

73 et al., 1981).

75 Process failures observed at elevated FOG loading rates have impeded the ability to fully exploit

76 higher biomethane production during FOG codigestion with municipal wastewater sludge

77 (Davidsson et al., 2008; Girault et al., 2012; Luostarinen et al., 2009; Noutsopoulos et al., 2013;

78 Wan et al., 2011; Wang et al., 2013). Specifically, the LCFA released during lipid hydrolysis can

79 inhibit anaerobic microorganisms at high concentrations (Angelidaki \& Ahring, 1992; Koster \&

80 Cramer, 1987; Lalman \& Bagley, 2000; Rinzema et al., 1994), thereby limiting their

81 bioconversion into methane. Causes of inhibition have been attributed to LCFA adsorption onto

82 cell surfaces, which can lead to direct toxicity (Hanaki et al., 1981; Rinzema et al., 1994) and/or

83 substrate transport limitations (Pereira et al., 2005). While aceticlastic methanogens are believed

84 to be the most sensitive group to LCFA toxicity (Koster and Cramer, 1987; Lalman and Bagley,

85 2000, 2001; Rinzema et al., 1994), the inhibition of hydrogenotrophic methanogens and

86 syntrophic bacteria by LCFA has also been suggested (Hanaki et al., 1981; Lalman and Bagley,

87 2002; Pereira et al., 2005; Roy et al., 1985). Reported threshold values for FOG loading that led

88 to decreased methane yields during codigestion with municipal wastewater sludge ranged from

$89 \sim 0.4$ to $2.1 \mathrm{~g} \mathrm{VS} / \mathrm{L}-\mathrm{d}$ (Girault et al., 2012; Luostarinen et al., 2009; Noutsopoulos et al., 2013;

90 Silvestre et al. 2011; Wan et al., 2011; Wang et al., 2013). However, these empirical FOG

91 loading thresholds do not account for digester microbial populations and their role in LCFA

92 conversion, and are thus of limited use for predicting the response of a digester following

93 transient increases in FOG loading. An improved understanding of the relationship between

94 digester biomass composition and LCFA accumulation is needed to develop operational 
95 strategies for stable codigester operation with increased FOG loadings and enhanced methane

96 recovery.

98 The importance of biomass adaptation for stable FOG digestion has been indicated by previous

99 studies. Silvestre et al. (2011) observed that stepwise increases in FOG loading led to the

100 development of biomass with higher LCFA $\beta$-oxidation and methanogenic activities during

101 codigestion with municipal sludge. Alves et al. (2001) found that both the tolerance to LCFA

102 toxicity as well as the LCFA-biodegradation activity increased with long-term exposure to lipids

103 in an anaerobic fixed-bed bioreactor. Similarly, long-term acclimation was identified as a key

104 factor influencing the resilience to LCFA toxicity in a series of digester sludges exposed to skim

105 milk and oleate based wastewaters (Silva et al., 2014). While these results collectively indicated

106 that biomass adaptation could affect the efficiency of FOG conversion, the microbial community

107 structures of these digester sludges were not assessed. The dynamics of LCFA-degrading

108 microbial communities have been previously studied using highly enriched systems with LCFA

109 as the primary carbon source (Salvador et al., 2013; Shigematsu et al., 2006; Sousa et al., 2007a;

110 Ziels et al., 2015). However, the relationship between the LCFA conversion efficiency and

111 microbial community structure during FOG codigestion with municipal wastewater sludge has

112 received little attention. The changes in LCFA-degrading community structure caused by

113 transient increases in FOG loading therefore need further study to enable better predictions of

114 acceptable FOG loadings during codigestion.

115

116 The main objective of this study was to elucidate the relationship between digester biomass

117 composition and LCFA conversion rates and removal efficiency during FOG codigestion with 
118 municipal wastewater treatment sludge. Quantitative PCR targeting LCFA-degrading syntrophic

119 bacteria and methanogenic archaea was conducted along with Illumina 16S rRNA gene amplicon 120 sequencing of Bacteria and Archaea communities to monitor microbial population structure

121 changes in a FOG codigester and control digester treating municipal wastewater solids. The 122 specific goals were to: (1) determine the effects of FOG addition on the digester microbial 123 community structure, and (2) examine relationships between microbial community structure and 124 LCFA removal following transient variations in FOG loading.

125

126 


\subsection{Digester Operation}

130 Two semi-continuous complete-mix anaerobic digesters (4L working volume) were operated at

$13137^{\circ} \mathrm{C}$ with a 20 -day hydraulic retention time (HRT) for 198 days. The digesters were mixed with

132 axial flow impellers at 275-325 rpm. They were started with anaerobic digester sludge collected

133 from Henriksdal WWTP in Stockholm, Sweden, and were fed with a mixture of waste primary

134 sludge (WPS) and waste activated sludge (WAS) collected from the same plant throughout the

135 experiment. The WAS+WPS was collected biweekly and stored at $4{ }^{\circ} \mathrm{C}$. The digesters were

136 manually fed once daily by withdrawing the volume of reactor liquid corresponding to the

137 volume of the feed prior to addition. The average feed WPS+WAS volatile solids (VS)

138 concentration was $28 \pm 2 \mathrm{~g} \mathrm{VS} / \mathrm{L}$ and the feed sludge VS loading rate (VSLR) for both digesters

139 averaged $1.4 \pm 0.1 \mathrm{~g} \mathrm{VS} / \mathrm{L}$-day over the course of the experiment. After an initial startup period

140 of 53 days of only feeding WPS+WAS, waste cooking oil (hereby referred to as FOG) from a

141 nearby restaurant was added to one of the digesters for codigestion. The start of FOG codigestion

142 was defined as day 1 of the experimental period (Table 1). The FOG VS content was $\sim 99 \%$, and

143 its addition to the codigester was increased in a stepwise manner over time to $1.5 \mathrm{~g} \mathrm{VS} / \mathrm{L}-\mathrm{d}$ (52\%

144 of the total feed VS) by day 94 (Table 1).

145

146

147

148

149 Digester performance was monitored with daily biogas production, methane content, $\mathrm{pH}$, effluent

150 volatile fatty acid (VFA), effluent LCFA, total solids (TS), and VS. Biogas production was

151 measured with tipping bucket displacement gas meters (MilliGascounters, Ritter, Germany). The

152 biogas composition was analyzed weekly for methane, carbon dioxide, oxygen, and hydrogen 
153 sulfide using a portable gas analyzer (Biogas Check, Geotech, UK). All measured gas volumes

154 are reported at standard temperature and pressure $\left(1 \mathrm{~atm}\right.$ pressure and $\left.0^{\circ} \mathrm{C}\right)$. The TS and VS

155 contents of the sludge were determined according to Swedish Standard Method SS028311. The

$156 \mathrm{pH}$ of the digesters was measured using an Inolab $\mathrm{pH} 7310$ meter (InoLab, Wissenschaftlich-

157 Technische Werkstätten, Germany) immediately after withdrawing sludge from the reactors.

158 VFA (acetate, propionate, butyrate, iso-butyrate, valerate, iso-valerate, capronate and iso-

159 capronate) were analyzed by GC-FID (HP 6890, Hewlett Packard), and were separated with a

160 BP21 (FFAP) column $(30 \mathrm{~m} \times 0.32 \mathrm{~mm} \times 0.25 \mu \mathrm{m}$, SGE Analytical Science $)$ as described

161 previously (Jonsson and Borén, 2002). LCFA were measured according Ziels et al. (2015) with

162 minor modifications. Briefly, $10 \mathrm{~mL}$ of digester sludge was centrifuged at $10,000 \times \mathrm{g}$ for $10 \mathrm{~min}$,

163 and immediately decanted. Approximately $0.2 \mathrm{~g}$ of pelleted sludge was transferred to a pre-

164 weighed glass extraction vial, which was then dried at $80^{\circ} \mathrm{C}$ for $15 \mathrm{hr}$, allowed to cool, and

165 reweighed. $1 \mathrm{~mL}$ of water was then added to the sample, and the subsequent LCFA extraction

166 and quantification was conducted as described by Ziels et al. (2015). The average recovery of

167 palmitate $\left(\mathrm{C}_{16: 0}\right)$, stearate $\left(\mathrm{C}_{18: 0}\right)$, and oleate $\left(\mathrm{C}_{18: 1}\right)$ spiked to digester sludge samples was $100 \%$,

$16892 \%$, and $83 \%$, respectively.

169

170

171

172 Batch methanogenic activity tests were conducted with biomass from both digesters in order to

173 determine the maximum conversion kinetics of acetate and oleate on days 0,65 , and 135 ,

174 according to the protocol by Karlsson et al. (2012). Briefly, $15 \mathrm{~mL}$ digester sludge aliquots

175 (0.17-0.19 g VS) were directly transferred into $160 \mathrm{~mL}$ glass serum bottles containing $130 \mathrm{~mL}$ of

176 anaerobic basal medium prepared according to Karlsson et al. (2012), and were then sealed with

177 butyl rubber septa. The bottles were flushed with a mixture of $\mathrm{O}_{2}$-free $80: 20 \mathrm{~N}_{2}: \mathrm{CO}_{2}$ to ensure 
178 anaerobic conditions. Substrate (either sodium acetate or oleic acid) was then added to an initial

179 concentration of $5 \mathrm{mM}$. Control vials without any added substrate were also included in each

180 batch test. All treatments were run in triplicate, and were maintained at $37^{\circ} \mathrm{C}$ for approximately

$181260 \mathrm{~h}$ without mixing. The gas production was measured based on the pressure increase in the

182 bottles using a handheld pressure transducer (Testo 3123, Testo, Sparta, New Jersey). The

183 methane content of the headspace was measured in triplicate by GC-FID (Hewlett Packard, 5880

184 A) at each gas pressure sampling point. The methane production in the control vials was

185 subtracted from the substrate-amended vials to determine the methane production attributed to

186 substrate conversion.

188 A modified Gompertz equation was used to describe the inoculum-corrected methane production 189 curves in the batch kinetic assays, as proposed by Palatsi et al. (2012) and Silva et al. (2014):

$$
M(t)=P \cdot \exp \left[-\exp \left[\frac{q_{\max } \cdot e}{P}(\lambda-t)+1\right]\right]
$$

191 where $M$ is the accumulated methane $\left(\mathrm{mL} \mathrm{CH}_{4} / \mathrm{L}\right)$ at time $=t$ (days), $P$ is the maximum

192 cumulative methane production $\left(\mathrm{mL} \mathrm{CH}_{4} / \mathrm{L}\right), q_{\max }$ is the maximum methane production rate $(\mathrm{mL}$

$193 \mathrm{CH}_{4} / \mathrm{L}$-day), $e$ is 2.7182818 , and $\lambda$ is the lag-phase time (days). All methane generation terms are

194 in reference to standard temperature and pressure. The model fitting and parameter standard error 195 estimation was conducted with nonlinear regression in $\mathrm{R}$ version 3.0.2.

\subsection{Analysis of Microbial Community Structure}

\subsubsection{DNA Extraction and Quantification}

200 Digester biomass samples were collected for DNA analysis on days 0, 37, 51, 64, 114 and 138

201 from the FOG codigester and on days $0,64,86$ and 138 from the control. The samples were 
202 prepared by transferring $10 \mathrm{~mL}$ of digester sludge aliquots directly into sterile $15 \mathrm{~mL}$ tubes,

203 immediately centrifuging at $10,000 \times \mathrm{g}$ for $10 \mathrm{~min}$ at $4^{\circ} \mathrm{C}$, carefully decanting the supernatant,

204 and storing the remaining pellet at $-20^{\circ} \mathrm{C}$. DNA was isolated from approximately $0.2 \mathrm{~g}$ of wet

205 solids using the PowerSoil ${ }^{\circledR}$ RNA/DNA Isolation Kit (MO BIO, Inc, Carlsbad, California)

206 according to the manufacturer's instructions. The concentration of extracted DNA was

207 immediately measured with the Quant-IT dsDNA High Sensitivity Assay Kit with a Qubit 2.0

208 flourometer (Invitrogen, Carlsbad, California). Triplicate DNA extractions were analyzed at each

209 sampling date to estimate variance in population abundances and ensure that observed changes in

210 community structure were not due to technical error. Extracted DNA was stored in nuclease-free

211 water at $-20^{\circ} \mathrm{C}$.

212

214 Reaction contents and thermocycling conditions for qPCR analysis were as described by Ziels et

215 al. (2015). qPCR analysis on syntrophic LCFA $\beta$-oxidizing bacteria was conducted targeting 16S

216 rRNA genes of the genera Syntrophomonas and Syntrophus using the primers and probes

217 developed by Ziels et al. (2015), as these primers/probes were the only established TaqMan

218 qPCR assays targeting these syntrophic $\beta$-oxidizing bacterial groups at this time. Additionally,

219 qPCR analysis was conducted targeting the domain Bacteria, the methanogenic archaeal orders

220 of Methanomicrobiales, Methanobacteriales, Methanococcales, and the methanogenic archaeal

221 families of Methanosarcinaceae and Methanosaetaceae using previously developed

222 primer/probe sets (Yu et al., 2005). Further details on the qPCR primer/probe sets used in this

223 study are provided in Supplementary Table 1. All samples were analyzed in duplicate. No-

224 template controls (NTCs) were included with each qPCR run. Extracted DNA from the digester 
225 biomass samples was diluted 1:10 in nuclease-free water to prevent PCR inhibition. Calibration

226 standards for the qPCR assays were prepared as described by Ziels et al. (2015), and were

227 included in duplicate in each qPCR run for all target groups. The strains from which 16S rRNA

228 gene sequences were used to construct the calibration standards are given in Supplementary

229 Table 1, along with the average slopes and intercepts of the qPCR calibration curves.

232 Selected DNA extracts were processed for high-throughput amplicon sequencing on the Illumina

233 MiSeq platform, using the protocol described by Ziels et al. (2015). Briefly, two-step nested PCR

234 was conducted prior to sequencing to enhance sensitivity. Bacteria and Archaea sequence

235 libraries were generated separately for each sample by using different primer sets in the initial

236 PCR. The primers used in the initial PCR for the Bacteria sequence library generation were a

237 modified 341F (5'-CCTAYGGGRBGCASCAG-3') and a modified 806R (5'-

238 GGACTACNNGGGTATCTAAT-3') (Sundberg et al., 2013), and for the Archaea sequence

239 library the primers Arch-349F (5'-GYGCASCAGKCGMGAAW-3') and Arch-915R (5'-

240 GTGCTCCCCCGCCAATTCCT-3') were used. PCR amplification, purification, and library

241 construction were conducted in accordance to Ziels et al. (2015). Libraries were sequenced with

242 an Illumina MiSeq at the University of Copenhagen Molecular Microbial Ecology Lab.

243 Sequences were submitted to the NCBI Sequence Read Archive as BioProject PRJNA301747.

245 Paired-end sequences were joined using the fastq-join method (Aronesty, 2013) with a minimum

246 overlap of $100 \mathrm{bp}$ and a zero percent difference allowed in the overlap region. The UPARSE

247 method was used to trim sequences to $298 \mathrm{bp}$ and filter sequences based on a maximum 
248 estimated error of 0.05 using USEARCH61 (Edgar, 2010; Edgar et al., 2011). Sequence

249 chimeras were identified against the RDP Gold reference database (v.9) included in the

250 UCHIME distribution (Edgar et al., 2011) within the QIIME pipeline v.1.8.0 (Caporaso et al.,

251 2010). Filtered sequences were clustered into operational taxonomic units (OTUs) based on 3\%

252 sequence divergence using USEARCH61 (Edgar, 2010). Representative sequences of each OTU

253 were identified based on the cluster seed, and were classified using a naïve Bayesian algorithm

254 with the Ribosomal Database Project (RDP) Classifier program version 2.2 (Wang et al., 2007).

255 For the Bacteria sequence libraries, Archaea sequences were removed prior to further analysis,

256 and similarly Bacteria sequences were filtered and removed from Archaea sequence libraries. A

257 total of 1,442,363 quality-filtered reads were obtained from the Illumina sequencing of Bacteria

258 16S rRNA gene amplicons ( $n=21$ samples), and 1,312,584 quality-filtered reads were obtained

259 from sequencing of Archaea 16S rRNA gene amplicons ( $n=21$ samples).

260

261 Multivariate statistical analysis and diversity metrics were calculated using the vegan library

262 version 2.0 .10 (Oksanen et al., 2007) in $\mathrm{R}$ version 3.0.2. Canonical correspondence analysis

263 (CCA) was performed using sequence counts (scaled to equal reads per sample) for OTUs that

264 were present above $1 \%$ of the population in at least one sample. The environmental parameters

265 that maximized the model significance were identified using forward-backward selection based

266 on P-values. Bray-Curtis distance matrices were calculated after rarefying samples to an equal

267 number of reads. Diversity calculations were performed on entire sample sequence libraries

268 (rarefied to equal reads) excluding singleton OTUs. Richness was calculated as the number of

269 OTUs after rarefying to the smallest number of reads per sample. Hill numbers were used to

270 measure diversity based on effective species numbers $\left({ }^{q} D\right)$ at varying orders $(q=0,1,2)$ (Hill, 
271 1973; Jost, 2006). Diversity of order 0 (i.e. ${ }^{0} D$ ) is equal to species richness, while ${ }^{1} D$ is equal to $272 \exp \left(\right.$ Shannon entropy), and ${ }^{2} D$ is equivalent to $1 /($ Simpson concentration) (Hill, 1973; Jost, 273 2006). Diversity of order ${ }^{1} D$ weights species frequencies equally, while diversity of $\operatorname{order}^{2} D$ 274 disproportionally emphasizes dominant species (Jost, 2006; Vuono et al., 2015).

275

276 


\section{RESULTS}

3.1 FOG codigestion led to enhanced methane production and higher LCFA conversion kinetics

Two parallel anaerobic digesters were operated to compare differences in performance between

282 FOG codigestion with WPS+WAS and the digestion of only WPS+WAS for 145 days (Table 1).

283 By day 94 after FOG codigestion was commenced, the FOG VSLR reached $1.5 \mathrm{~g}$ VS/L-d (52\%

284 of the total VSLR w/w), corresponding to an increase in the total VSLR to the codigester of 2.1-

285 times relative to the control (2.9 versus $1.4 \mathrm{~g} / \mathrm{L}-\mathrm{d}$ ) (Fig. 1A). Accordingly, the daily methane

286 production significantly increased by 2.7 -times in the FOG codigester $\left(5200 \mathrm{~mL} \mathrm{CH}_{4} / \mathrm{d} \pm 560\right)$

287 relative to the control $\left(1900 \mathrm{~mL} \mathrm{CH}_{4} / \mathrm{d} \pm 200\right)$ at the highest VSLR $(p<1 \mathrm{e}-3$, unpaired t-test;

288 Fig. 1B). Due to the high VS concentration of the added FOG, the HRT of the codigester was

289 only decreased by $3 \%$ to 19.4 days at the highest VSLR. Thus, codigesting FOG at a VSLR of

$2901.5 \mathrm{~g}$ FOG VS/L-d resulted in about 2.7-times the daily methane production with no significant

291 process penalty in the digester HRT.

293 The specific methane yield on a VS-basis also increased by $31 \%$ in the FOG codigester (420 mL

$\left.294 \mathrm{CH}_{4} / \mathrm{g} \mathrm{VS}_{\text {fed }} \pm 40\right)$ relative to the control $\left(320 \mathrm{~mL} \mathrm{CH}_{4} / \mathrm{g} \mathrm{VS}_{\text {fed }} \pm 70\right)$ at the highest VSLR $(p<$

295 1e-3), indicating that the added FOG was more biodegradable than the WPS+WAS. The higher

296 degree of biodegradability of the added FOG was further supported by the significantly higher

297 VS reduction in the FOG codigester over the control throughout the experimental period,

298 achieving $63 \% \pm 4$ versus $51 \% \pm 5(p<1 \mathrm{e}-3$, unpaired $\mathrm{t}$-test). Assuming that the VS reduction of

299 the feed WPS+WAS in the FOG codigester was similar to the control digester (i.e. 51\%), the VS

300 reduction of the feed FOG in the codigester was estimated to be $74 \%$ during the highest FOG

301 VSLR. Consequently, the specific LCFA concentration in the codigester effluent increased to a 
302 maximum of $104 \pm 11 \mathrm{mg} \mathrm{LCFA} / \mathrm{g}$ TS on day 114 of FOG addition, in comparison to $4 \pm 0.5 \mathrm{mg}$

303 LCFA/g TS in the control (Fig. 1D). Thus, the 74\% reduction in FOG VS at the highest loading

304 rate resulted in LCFA accumulation within the codigester.

\section{[Figure 1]}

308 The $\mathrm{pH}$ was slightly reduced (Fig. 1C) after day 50 of FOG codigestion when the LCFA 309 concentration increased (Fig. 1D). The VFA concentration never exceeded $100 \mathrm{mg} / \mathrm{L}$ in both 310 digesters (data not shown), indicating that the codigester had sufficient VFA consumption

311 capacity at the prevailing LCFA conversion rates. LCFA were therefore the major intermediate

312 metabolites that accumulated during FOG degradation (Fig. 1D). The LCFA in the codigester

313 effluent were comprised of $38 \%$ palmitic, $16 \%$ stearic, and $46 \%$ oleic acids on average

314 (Supplementary Figure 1).

316 The maximum methane production rates $\left(q_{\max }\right)$ of both digester sludges were determined in batch

317 assays (on days 0,65 , and 135) fed with either acetate or oleate to compare the kinetic capacities

318 of the digester populations over time. The $q_{\max }$ of oleate-fed batch kinetic assays were

319 significantly increased for the FOG codigester sludge from $45 \pm 5$ on day zero to $110 \pm 5 \mathrm{~mL}$

$320 \mathrm{CH}_{4} / \mathrm{L}$-d by day 65 (Fig. 2A), corresponding to an increase of 2.4-times relative to the control.

321 Yet, the oleate $q_{\max }$ for the FOG codigester on day 135 was similar to day 65 ( $p>0.1$; Fig. 2A).

322 Similar $q_{\max }$ values in the acetate-fed batch assays were also observed between the codigester and 323 control for all batch tests (Fig. 2B); the acetate $q_{\max }$ increased between days zero and 65 and then 324 stabilized for both systems. These results indicate that FOG codigestion resulted in elevated 
325 oleate degradation kinetics, and that the codigester community reached a its maximum rate of

326 LCFA conversion by day 65.

327

328

329

330

331

332

333

334

335 Analysis of the Bacteria community diversity showed that Hill numbers of orders ${ }^{1} D$, and ${ }^{2} D$

336 substantially increased in the FOG codigester by the end of the experimental period

337 (Supplementary Figure 2). The taxonomic richness $\left({ }^{0} D\right)$ of the Bacteria community in the FOG

338 codigester did not change by day 138 ( $p>0.1$, unpaired t-test), while diversities of $\operatorname{order}^{1} D$ and

$339{ }^{2} D$ in the FOG codigester increased by 3.0-times and 4.6-times relative to the control,

340 respectively ( $p<0.001$, unpaired t-test; Supplementary Figure 2 ). While it is apparent that the

341 diversity of Bacteria was substantially elevated at the orders ${ }^{1} D$ and ${ }^{2} D$ in the FOG codigester

342 versus the control, the larger relative increase in diversity of $\operatorname{order}^{2} D$ indicates that the addition

343 of FOG had a larger influence on the diversity of dominant bacterial species.

345 The increase in the diversity of Bacteria in the FOG codigester occurred concomitantly with the

346 significant growth of $\beta$-oxidizing Syntrophomonas within the Bacteria community.

347 Syntrophomonas relative abundance in the Bacteria community increased to $14 \% \pm 0.7$ in the

348 FOG codigester over the experimental period but remained below 3\% relative abundance in the

349 control digester, as measured by qPCR (Fig. 3A). In contrast, the other known LCFA $\beta$-oxidizing

350 genus, Syntrophus, was measured by qPCR at less than $0.03 \%$ of the Bacteria community in both

351 digesters (Fig. 3B). The Syntrophus abundance significantly decreased from day zero to 86 in 
352 both digesters $(p<1 \mathrm{e}-3)$, but returned to its initial level in the FOG codigester by day 138 . The

353 enrichment of Syntrophomonas within the Bacteria community was corroborated by $16 \mathrm{~S}$ rRNA

354 gene amplicon sequencing, which showed that Syntrophomonas became the dominant genus in

355 the Bacteria sequence library by day 138 (Fig. 4). Syntrophomonas significantly increased in the

356 FOG codigester Bacteria sequence library from $1.2 \% \pm 0.3$ initially to $9.0 \% \pm 1.0$ by day 138 ( $p$

$357=0.009$, paired t-test), but stayed below $2 \%$ in the control (Fig 4). Gelria was another genus that

358 also increased in the FOG codigester Bacteria sequence library relative to the control (Fig. 4).

359 On the other hand, Petrimonas was initially the dominant bacterial genus in both digesters with a

360 relative sequence abundance of $\sim 20 \%$, but had a significantly lower relative sequence abundance

361 in the FOG codigester at $4.0 \% \pm 2.2$ by day $138(p=0.03$, paired t-test; Fig. 4$)$. Smithella also

362 significantly decreased from $6.2 \% \pm 0.9$ to $1.7 \% \pm 0.3$ relative sequence abundance in the FOG

363 codigester Bacteria community ( $p=0.01$, paired t-test), but increased from $6.7 \% \pm 0.1$ to $12 \% \pm$

3644.5 in the control (Fig. 4). Bray-Curtis dissimilarity values relative to the initial Bacteria

365 community structure (day zero) significantly increased between days $37(0.44 \pm 0.04)$ to 138

$366(0.61 \pm 0.03)$ in the FOG codigester $(p<1 \mathrm{e}-3$, paired t-test), whereas no significant changes in

367 Bray-Curtis dissimilarity values occurred in the control Bacteria community over time $(p>0.1$;

368 Supplementary Figure 3). These results demonstrate that FOG codigestion resulted in changes in

369 the Bacteria community structure, primarily attributed to the growth of the initially rare members

370 of Syntrophomonas and Gelria and the washout of initially dominant bacterial members such as

371 Petrimonas and Smithella (Fig. 4).

372

373 [Figure 3]

374

375

[Figure 4]

376 
378 In contrast to changes in Bacteria diversity, Hill diversity of orders ${ }^{1} D$, and ${ }^{2} D$ for the Archaea

379 showed a decreasing trend in the FOG codigester over the experimental period (Supplementary

380 Figure 4). Notably, the diversity of orders ${ }^{1} D$, and ${ }^{2} D$ for Archaea in the FOG codigester on day

381138 were $6 \%$ and $8 \%$ of that for Bacteria, respectively. Archaea species richness $\left({ }^{0} D\right)$ for the

382 FOG codigester and control were $34 \%$ and $51 \%$ of that for Bacteria on day 138 , respectively.

383 These results indicate that the diversity of Archaea was less than that of the Bacteria 384 communities in both digesters.

386 Significant changes in the Archaea community structure and abundance were observed with 387 FOG codigestion. The fraction of methanogenic archaea 16S rRNA gene concentration in the 388 prokaryotic community (calculated as the sum of all methanogen groups targeted by qPCR 389 divided by total methanogens + Bacteria) increased 8-times by day 138 in the FOG codigester 390 relative to the control ( $p<1 e-3$, unpaired t-test; Fig. 5). The methanogenic archaea 16S rRNA 391 gene concentration comprised over $20 \%$ of the prokaryotic community by the end of the 392 experimental period, while that of the control digester was $2.5 \%$ (Fig. 5). Bray-Curtis 393 dissimilarity values relative to the initial Archaea community structure significantly increased in 394 the FOG codigester between days $37(0.29 \pm 0.08)$ and $138(0.62 \pm 0.10)(p<1 \mathrm{e}-3$, paired t-test $)$

395 (Supplementary Figure 5). The increase in Bray-Curtis dissimilarity of the codigester Archaea 396 community relative to its initial population reveals that the addition of FOG resulted in changes 397 in the Archaea community structure. A significant increase in the hydrogenotrophic 398 Methanospirillum relative sequence abundance from $1.3 \% \pm 0.4$ to $34 \% \pm 3.0$ occurred between 399 day zero and 138 in the FOG codigester $(p=0.002$, paired t-test; Fig. 6). In contrast, 400 Methanospirillum stayed below 3\% relative sequence abundance in the control digester (Fig. 6). 
401 Methanosaeta was the dominant aceticlastic genus within the FOG codigester, increasing from a

402 relative concentration of $23 \% \pm 9$ on day zero to $46 \% \pm 5$ by day $138(p=0.01$; Fig. 6). Pearson

403 correlation coefficients between the average relative sequence abundances of Methanospirillum

404 and Methanosaeta with Syntrophomonas in the FOG codigester were 0.90 and 0.96, respectively.

405 Methanospirillum and Methanosaeta species were therefore key methanogenic groups growing

406 along with Syntrophomonas in the codigester microbiome during the degradation of FOG.

407

408

409

410

411

412

413

414

415

416

417

418

419

420

421 422 days). Analysis of variance (ANOVA) on the CCA models showed that the selected 423 environmental variables were significant in constraining both Bacteria and Archaea OTU

424 abundances $(p<0.05)$. The fractions of the total variability that was explained through the CCA 425 models were $69 \%$ and 67\% for the Bacteria and Archaea OTU abundance datasets, respectively.

426

427

[Figure 7]

\section{[Figure 5]}

[Figure 6]

\subsection{Microbial community structure was related to reactor performance during FOG codigestion}

Canonical correspondence analysis (CCA) was utilized to elucidate potential relationships between environmental and operational digester parameters and Bacteria and Archaea OTU sequence abundances within the digester samples (Fig. 7). The four environmental gradients found to be most effective at explaining the community abundance data for Bacteria and Archaea were: daily methane production rate, maximum methane production rate from oleate $\left(q_{\text {max }, \text { oleate }}\right)$, maximum methane production rate from acetate $\left(q_{\text {max,acetate }}\right)$, and time (experimental 
429 To further evaluate whether microbial community structure was related to system performance

430 during FOG degradation, a parameter was developed to relate the food-to-microorganism ratio

$431(F: M)$ for FOG loading to the LCFA-degrading microbial population within the codigester. Due

432 to the significant increase in Syntrophomonas abundance in the codigester relative to the control

433 (Fig. 3A and Fig. 4), we investigated whether Syntrophomonas abundance could serve as a

434 predictor for LCFA-degradation activity. A parameter termed the FOG-to-syntroph feed ratio

435 (F:M $\left.M_{\text {Synt }}\right)$ was thereby developed by normalizing the FOG loading to the concentration of

436 Syntrophomonas in the digester:

$$
F: M_{S y n t}=\frac{Q \times V S_{F O G}}{V \times X_{V S} \times f_{S y n t}}
$$

438 where: $Q$ is the daily feed volume (L/d), $V S_{F O G}$ is the influent FOG VS concentration (g VS/L),

$439 V$ is the reactor working volume $(\mathrm{L}), X_{V S}$ is the reactor VS concentration $(\mathrm{g} \mathrm{VS} / \mathrm{L})$, and $f_{\text {Synt }}$ is the

440 specific concentration of Syntrophomonas based on qPCR (16S rRNA copies/g VS). The F:M $M_{\text {Synt }}$

441 was calculated based on a 10-day average of daily FOG VS loading, a 10-day average of the

442 reactor VS concentration, and the specific concentration of Syntrophomonas 16S rRNA genes

443 per g VS on the day of the LCFA measurement.

445 The effluent LCFA concentration in the codigester was positively correlated to the $F: M_{\text {Synt }}\left(R^{2}\right.$ of 446 nonlinear regression $=0.94)$, indicating that the LCFA removal efficiency was related to the 447 abundance of Syntrophomonas biomass within the codigester (Fig. 8). Specific FOG loading 448 rates of 0 to $1.5 \times 10^{-12} \mathrm{~g}$ VS/16S gene copies-day resulted in effluent LCFA concentrations below $44930 \mathrm{mg} \mathrm{LCFA} / \mathrm{g}$ TS, whereas LCFA accumulated up to $104 \mathrm{mg} \mathrm{LCFA} / \mathrm{g}$ TS at higher F:M $M_{\text {Synt }}$ 450 values.

$451 \quad$ [Figure 8] 


\section{DISCUSSION}

455 High FOG loadings during codigestion with municipal sludge have led to process upsets

456 (Davidsson et al., 2008; Girault et al., 2012; Luostarinen et al., 2009; Noutsopoulos et al., 2013;

457 Wang et al., 2013) and even delayed process recovery (Wan et al., 2011). Threshold FOG

458 loading limits for codigestion have been recommended (Noutsopoulos et al., 2013; Wang et al.,

459 2013), but these loading limits have not considered the impacts of microbial community

460 adaptation. In our study, changes in microbial community structure were closely monitored

461 during transient increases in FOG loading, which showed that LCFA accumulation was related to

462 both the FOG loading rate and the abundance of syntrophic $\beta$-oxidizing consortia. LCFA

463 accumulated at higher specific loading rates of FOG relative to the abundance of

464 Syntrophomonas 16S rRNA genes in the codigester. Thus, previous reports of unstable digester

465 performance at high FOG loadings (Davidsson et al., 2008; Girault et al., 2012; Luostarinen et

466 al., 2009; Noutsopoulos et al., 2013; Wan et al., 2011; Wang et al., 2013) could possibly have

467 been attributed to an insufficient abundance of LCFA-degrading syntrophic bacteria, so that

468 LCFA accumulated to a concentration high enough to inhibit methanogenic activity (Angelidaki

469 \& Ahring, 1992; Hanaki et al., 1981; Rinzema et al., 1994). The significant growth of LCFA-

470 degrading syntrophic bacteria and methanogenic archaea in the FOG codigester in this study

471 supports previous observations that gradual stepwise increases in FOG loading stimulated higher

472 rates of LCFA $\beta$-oxidation and methanogenesis (Silvestre et al., 2011) and that biomass

473 resilience to LCFA was impacted by the exposure time to lipids (Alves et al., 2001; Silva et al.,

474 2014). Our finding that LCFA conversion efficiency depends upon the digester biomass

475 composition may also help to explain some of the variation in reported threshold limits of FOG 
476 loading during municipal sludge codigestion, which ranged from $\sim 0.4$ to $2.1 \mathrm{~g}$ FOG VS/L-d

477 (Girault et al., 2012; Luostarinen et al., 2009; Noutsopoulos et al., 2013; Silvestre et al. 2011;

478 Wan et al., 2011; Wang et al., 2013). The highest FOG VSLR tested in this study was $1.5 \mathrm{~g}$

$479 \mathrm{VS} / \mathrm{L}-\mathrm{d}$, which is close to the FOG VSLR threshold of $1.6 \mathrm{~g} \mathrm{VS} / \mathrm{L}-\mathrm{d}$ reported previously during

480 FOG codigestion with municipal sludge by Luostarinen et al. (2009). At our highest FOG VSLR,

481 LCFA accumulated to $104 \mathrm{mg}$ LCFA/g TS with no appreciable increase in VFA. This

482 phenomenon was also observed by Silvestre et al. (2011) and Girault et al. (2012) during FOG

483 codigestion with municipal sludge, suggesting that acetogenesis from LCFA can be rate-limiting

484 in such processes. The decrease in effluent LCFA in the codigester on day 138 in our study thus

485 indicates that a higher FOG VSLR may be possible after further time for microbial community

486 adaptation. Overall, these results implicate that the FOG loading threshold during codigestion

487 may be considered a 'moving target' that relies upon the degree of microbial community

488 adaptation and the activity within the digester microbiome to degrade LCFA.

490 This is the first study to monitor changes in syntrophic $\beta$-oxidizing bacteria abundance during

491 FOG codigestion by qPCR, which highlighted a differential selection of Syntrophomonas over

492 Syntrophus. The family of Syntrophomonadaceae has been previously identified as key

493 syntrophic bacteria enriched in anaerobic digester biomass during unsaturated LCFA degradation

494 (Baserba et al., 2012; Sousa et al., 2009, 2007a; Ziels et al., 2015). In contrast, Syntrophaceae

495 have been detected at higher abundances in anaerobic communities degrading saturated LCFA

496 (Sousa et al., 2009) as well as long-chain alkanes (Gray et al., 2011; Zengler et al., 1999). While

497 the saturated fatty acids of palmitate $\left(\mathrm{C}_{16: 0}\right)$ and stearate $\left(\mathrm{C}_{18: 0}\right)$ together comprised $54 \%$ of the

498 LCFA in the codigester effluent on average (Supplementary Figure 1), it is not known whether 
499 the LCFA composition of the influent FOG influenced the selection of Syntrophomonas over

500 Syntrophus. It may be also possible that the enrichment of Syntrophomonas in the codigester was

501 attributed to specific syntroph-methanogen pairings with Methanospirillum and Methanosaeta,

502 which were the dominant methanogenic archaeal groups enriched with FOG addition and were

503 strongly correlated with Syntrophomonas abundance (i.e. Pearson coefficients $>0.9$ ).

504

505 The positive association of the FOG codigester Bacteria and Archaea community profiles with

506 the constrained gradients of daily methane production and $q_{\max , \text { oleate }}$ further confirm that changes

507 in microbial community structure were related to measures of codigester performance. Hill

508 diversity numbers also proved to be effective metrics to capture the alpha and beta components

509 of community structure changes within the digesters, as was similarly found with other

510 biological wastewater treatment processes (Vuono et al., 2015). Diversity numbers of orders ${ }^{1} D$

511 and ${ }^{2} D$ for the Bacteria community increased along with measures of reactor performance in the

512 FOG codigester, but the same was not true with species richness $\left({ }^{0} D\right)$. This agrees with previous

513 findings indicating that higher order diversity (i.e. evenness) in digester Bacteria communities

514 correlated positively with COD removal and methane production, whereas species richness did

515 not (Werner et al., 2011). While the Bacteria species richness of the FOG codigester remained

516 stable in this study, the community experienced changes in dominant members (captured by ${ }^{2} D$ )

517 that contributed to higher ecosystem function. The higher methane production of the codigester

518 following shifts in dominant Bacteria community members (higher ${ }^{2} D$ ) coincided with the

519 growth of the functionally specific Syntrophomonas. The increased biodiversity within the

520 codigester was therefore attributed to the growth of initially rare syntrophic bacteria, which were

521 also a driving force behind improvements in the codigester daily methane production and 
522 increased values of $q_{m a x, \text { oleate. }}$ This finding agrees with previous observations that the abundance

523 of syntrophic bacteria was linked to anaerobic digester resilience (Regueiro et al., 2015; Werner

524 et al., 2011).

525

526 Evaluating the activity of syntrophic fatty acid-oxidizing bacteria has previously been proposed

527 as an alternative approach to gauge the activity of methanogenic pathways, since the metabolism

528 of syntrophic fatty acid-oxidizing bacteria is directly coupled to the activity of methanogens

529 (Smith et al., 2015). Our proposed relationship between LCFA removal and the Syntrophomonas

530 16S rRNA gene concentration was based on the assumption that Syntrophomonas was a major

531 syntrophic bacterial group involved in LCFA $\beta$-oxidation, and that Syntrophomonas biomass

532 could serve as a surrogate measure for the activity of the LCFA-degrading community

533 (syntrophic bacteria + methanogens). This assumption was supported by the observation that

534 LCFA were the primary metabolite of FOG degradation rather than acetate, indicating that

535 LCFA $\beta$-oxidation was not likely limited by aceticlastic methanogenesis. Similar to our findings,

536 the concentration of syntrophic bacterial biomass was recently found to be the limiting factor for

537 butyrate conversion via $\beta$-oxidation in non-defined methanogenic enrichments (Junicke et al.,

538 2016). Ziels et al. (2015) also found that the relative fraction of Syntrophomonas in the Bacteria

539 community of oleate-fed anaerobic enrichments was positively correlated with the specific

540 methane production rate. Since the thermodynamics of LCFA-degradation hinges upon the

541 activity of methanogenic archaea and syntrophic $\beta$-oxidizing bacteria (Schink, 1997), we propose

542 that the FOG-loading capacity of a given digester can be better predicted by closely monitoring

543 the abundance and activity of those populations. 
545 From a process engineering perspective, efficient turnover of LCFA is critical for maintaining

546 the maximum kinetic capacity of the digester community (Pereira et al. 2005). The positive

547 correlation observed between the effluent LCFA concentration and the codigester F:M $M_{\text {Synt }}$

548 suggested that a higher biomass of syntrophic LCFA-degrading consortia could increase the

549 threshold loading rate of FOG during codigestion. A higher biomass of slow growing

550 Syntrophomonas has been associated with longer anaerobic digester solids retention times (Hao

551 et al., 2016; Lee et al., 2011). Therefore, the methane production of FOG codigestion processes

552 should be greater with longer solids retention times by allowing a higher mass loading of FOG

553 while maintaining an $F: M_{\text {Synt }}$ that supports low effluent LCFA concentrations. This work also

554 demonstrates the potential to minimize LCFA accumulation by controlling transient FOG

555 loading rates based on the analysis of the codigester community structure, such as with qPCR

556 measurements of syntrophic LCFA-degrading bacteria abundance. 


\section{CONCLUSIONS}

559 Microbial adaptation was important for the conversion of FOG into methane during codigestion

560 with municipal wastewater sludge. Syntrophomonas bacteria were the primary syntrophic $\beta$ -

561 oxidizing group that was enriched in the codigester microbiome. Increases in digester LCFA

562 concentrations occurred when the FOG loading rate relative to Syntrophomonas abundance

563 exceeded a threshold value. Changes in the FOG codigester and control digester microbiomes

564 were best explained through constrained ordination by measures of digester function. These

565 results collectively indicate that more efficient LCFA conversion into methane can be achieved

566 by strategically managing transient FOG loadings to allow sufficient time for microbial

567 community adaptation through higher abundances of LCFA-degrading consortia.

570 Acknowledgements

571 This research was funded by the Biogas Research Center at Linköping University, the U.S.

572 National Science Foundation Graduate Research Fellowship [grant DGE-1256082], and the U.S.

573 EPA [grant RD835567]. 
574

575

576

577

578

579

580

581

582

583

584

585

586

587

588

589

590

591

592

593

594

595

596

597

\section{References:}

Alves, M.M., Mota Vieira, J.A., Álvares Pereira, R.M., Pereira, M.A., Mota, M., 2001. Effects of lipids and oleic acid on biomass development in anaerobic fixed-bed reactors. Part II: Oleic acid toxicity and biodegradability. Water Res. 35, 264-270. doi:10.1016/S0043$1354(00) 00242-6$

Angelidaki, I., Ahring, B.K., 1992. Effects of free long-chain fatty acids on thermophilic anaerobic digestion. Appl. Microbiol. Biotechnol. 37, 808-812. doi:10.1007/BF00174850

Aronesty, E., 2013. Comparison of sequencing utility programs. Open Bioinform J 7, 1-8.

Baserba, M.G., Angelidaki, I., Karakashev, D., 2012. Effect of continuous oleate addition on microbial communities involved in anaerobic digestion process. Bioresour. Technol. 106, 74-81. doi:10.1016/j.biortech.2011.12.020

Caporaso, J.G., Kuczynski, J., Stombaugh, J., Bittinger, K., Bushman, F.D., Costello, E.K., Fierer, N., Peña, A.G., Goodrich, J.K., Gordon, J.I., Huttley, G.A., Kelley, S.T., Knights, D., Koenig, J.E., Ley, R.E., Lozupone, C.A., McDonald, D., Muegge, B.D., Pirrung, M., Reeder, J., Sevinsky, J.R., Turnbaugh, P.J., Walters, W.A., Widmann, J., Yatsunenko, T., Zaneveld, J., Knight, R., 2010. QIIME allows analysis of high-throughput community sequencing data. Nat. Methods 7, 335-336. doi:10.1038/nmeth.f.303

Cirne, D.G., Paloumet, X., Björnsson, L., Alves, M.M., Mattiasson, B., 2007. Anaerobic digestion of lipid-rich waste-Effects of lipid concentration. Renew. Energy 32, 965975. doi:10.1016/j.renene.2006.04.003

Davidsson, Å., Lövstedt, C., la Cour Jansen, J., Gruvberger, C., Aspegren, H., 2008. Codigestion of grease trap sludge and sewage sludge. Waste Manag. 28, 986-992. doi:10.1016/j.wasman.2007.03.024 
598 Edgar, R.C., 2010. Search and clustering orders of magnitude faster than BLAST. Bioinformatics 26, 2460-2461. doi:10.1093/bioinformatics/btq461

600 Edgar, R.C., Haas, B.J., Clemente, J.C., Quince, C., Knight, R., 2011. UCHIME improves sensitivity and speed of chimera detection. Bioinformatics 27, 2194-2200.

602 doi:10.1093/bioinformatics/btr381

603 Girault, R., Bridoux, G., Nauleau, F., Poullain, C., Buffet, J., Peu, P., Sadowski, A.G., Béline, F., 604 2012. Anaerobic co-digestion of waste activated sludge and greasy sludge from flotation process: Batch versus CSTR experiments to investigate optimal design. Bioresour. Technol. 105, 1-8. doi:10.1016/j.biortech.2011.11.024

Gray, N.D., Sherry, A., Grant, R.J., Rowan, A.K., Hubert, C.R.J., Callbeck, C.M., Aitken, C.M., Jones, D.M., Adams, J.J., Larter, S.R., Head, I.M., 2011. The quantitative significance of

Hanaki, K., Matsuo, T., Nagase, M., 1981. Mechanism of inhibition caused by long- chain fatty acids in anaerobic digestion process. Biotechnol. Bioeng. 23, 1591-1610.

615 Hao, L., Bize, A., Conteau, D., Chapleur, O., Courtois, S., Kroff, P., Desmond-Le Quéméner, E., Bouchez, T., Mazeas, L., 2016. New insights into the key microbial phylotypes of anaerobic sludge digesters under different operational conditions. Water Res. In Press. doi:10.1016/j.watres.2016.06.014

Hatamoto, M., Imachi, H., Fukayo, S., Ohashi, A., Harada, H., 2007. Syntrophomonas palmitatica sp. nov., an anaerobic, syntrophic, long-chain fatty-acid-oxidizing bacterium 
isolated from methanogenic sludge. Int. J. Syst. Evol. Microbiol. 57, 2137-2142.

623 doi:10.1099/ijs.0.64981-0

624 Hill, M.O., 1973. Diversity and Evenness: A Unifying Notation and Its Consequences. Ecology $625 \quad 54,427-432$. doi:10.2307/1934352

626 Jackson, B.E., Bhupathiraju, V.K., Tanner, R.S., Woese, C.R., McInerney, M.J., 1999.

627 Syntrophus aciditrophicus sp. nov., a new anaerobic bacterium that degrades fatty acids 628 and benzoate in syntrophic association with hydrogen-using microorganisms. Arch. $629 \quad$ Microbiol. 171, 107-114. doi:10.1007/s002030050685

630 Jonsson, S., Borén, H., 2002. Analysis of mono- and diesters of o-phthalic acid by solid-phase 631 extractions with polystyrene-divinylbenzene-based polymers. J. Chromatogr. A 963, $632 \quad 393-400$. doi:10.1016/S0021-9673(02)00647-7

633 Jost, L., 2006. Entropy and diversity. Oikos 113, 363-375. doi:10.1111/j.2006.0030$634 \quad 1299.14714 . x$

635 Junicke, H., Loosdrecht, M.C.M. van, Kleerebezem, R., 2016. Kinetic and thermodynamic 636 control of butyrate conversion in non-defined methanogenic communities. Appl.

637 Microbiol. Biotechnol. 100, 915-925. doi:10.1007/s00253-015-6971-9

638 Karlsson, A., Einarsson, P., Schnürer, A., Sundberg, C., Ejlertsson, J., Svensson, B.H., 2012. 639 Impact of trace element addition on degradation efficiency of volatile fatty acids, oleic 640 acid and phenyl acetate and on microbial populations in a biogas digester. J. Biosci. 641 Bioeng. 114, 446-452. doi:10.1016/j.jbiosc.2012.05.010

642 Koster, I.W., Cramer, A., 1987. Inhibition of Methanogenesis from Acetate in Granular Sludge 643 by Long-Chain Fatty Acids. Appl. Environ. Microbiol. 53, 403-409. 
644 Lalman, J.A., Bagley, D.M., 2001. Anaerobic degradation and methanogenic inhibitory effects of 645 oleic and stearic acids. Water Res. 35, 2975-2983. doi:10.1016/S0043-1354(00)00593-5

646 Lalman, J.A., Bagley, D.M., 2000. Anaerobic degradation and inhibitory effects of linoleic acid. 647 Water Res. 34, 4220-4228. doi:10.1016/S0043-1354(00)00180-9

648 Lalman, J., Bagley, D.M., 2002. Effects of C18 long chain fatty acids on glucose, butyrate and 649 hydrogen degradation. Water Res. 36, 3307-3313. doi:10.1016/S0043-1354(02)00014-3

650 Lee, I.-S., Parameswaran, P., Rittmann, B.E., 2011. Effects of solids retention time on 651 methanogenesis in anaerobic digestion of thickened mixed sludge. Bioresour. Technol. $652 \quad$ 102, 10266-10272. doi:10.1016/j.biortech.2011.08.079

653 Luostarinen, S., Luste, S., Sillanpää, M., 2009. Increased biogas production at wastewater 654 treatment plants through co-digestion of sewage sludge with grease trap sludge from a 655 meat processing plant. Bioresour. Technol. 100, 79-85.

656 doi:10.1016/j.biortech.2008.06.029

657 McInerney, M.J., 1992. The genus Syntrophomonas, and other syntrophic bacteria. Prokaryotes $658 \quad$ Springer N. Y. NY 2048-2057.

659 Noutsopoulos, C., Mamais, D., Antoniou, K., Avramides, C., Oikonomopoulos, P., Fountoulakis, 660 I., 2013. Anaerobic co-digestion of grease sludge and sewage sludge: The effect of 661 organic loading and grease sludge content. Bioresource Technology 131, 452-459. 662 doi:10.1016/j.biortech.2012.12.193

663 Oksanen, J., Kindt, R., Legendre, P., O’Hara, B., Stevens, M.H.H., Oksanen, M.J., Suggests, M., 664 2007. The vegan package. Community Ecol. Package. 
665 Palatsi, J., Affes, R., Fernandez, B., Pereira, M.A., Alves, M.M., Flotats, X., 2012. Influence of 666 adsorption and anaerobic granular sludge characteristics on long chain fatty acids 667 inhibition process. Water Res. 46, 5268-5278. doi:10.1016/j.watres.2012.07.008

668 Pereira, M.A., Pires, O.C., Mota, M., Alves, M.M., 2005. Anaerobic biodegradation of oleic and 669 palmitic acids: Evidence of mass transfer limitations caused by long chain fatty acid 670 accumulation onto the anaerobic sludge. Biotechnol. Bioeng. 92, 15-23. 671 doi:10.1002/bit.20548

672 Regueiro, L., Lema, J.M., Carballa, M., 2015. Key microbial communities steering the 673 functioning of anaerobic digesters during hydraulic and organic overloading shocks. Bioresour. Technol. 197, 208-216. doi:10.1016/j.biortech.2015.08.076

675 Rinzema, A., Boone, M., Knippenberg, K. van, Lettinga, G., 1994. Bactericidal Effect of Long 676 Chain Fatty Acids in Anaerobic Digestion. Water Environ. Res. 66, 40-49.

677 Roy, F., Albagnac, G., Samain, E., 1985. Influence of Calcium Addition on Growth of Highly 678 679 Purified Syntrophic Cultures Degrading Long-Chain Fatty Acids. Appl. Environ.

680 Salvador, A.F., Cavaleiro, A.J., Sousa, D.Z., Alves, M.M., Pereira, M.A., 2013. Endurance of 681 682 methanogenic archaea in anaerobic bioreactors treating oleate-based wastewater. Appl.

683 Schink, B., 1997. Energetics of syntrophic cooperation in methanogenic degradation. Microbiol. 684 Mol. Biol. Rev. 61, 262-280.

685 Shigematsu, T., Tang, Y., Mizuno, Y., Kawaguchi, H., Morimura, S., Kida, K., 2006. Microbial 686 diversity of mesophilic methanogenic consortium that can degrade long-chain fatty acids 687 in chemostat cultivation. J. Biosci. Bioeng. 102, 535-544. doi:10.1263/jbb.102.535 
688 Silva, S.A., Cavaleiro, A.J., Pereira, M.A., Stams, A.J.M., Alves, M.M., Sousa, D.Z., 2014.

689 Long-term acclimation of anaerobic sludges for high-rate methanogenesis from LCFA.

690 Biomass Bioenergy 67, 297-303. doi:10.1016/j.biombioe.2014.05.012

691 Silvestre, G., Rodríguez-Abalde, A., Fernández, B., Flotats, X., Bonmatí, A., 2011. Biomass

692 adaptation over anaerobic co-digestion of sewage sludge and trapped grease waste.

693 Bioresour. Technol. 102, 6830-6836. doi:10.1016/j.biortech.2011.04.019

694 Smith, A.L., Skerlos, S.J., Raskin, L., 2015. Anaerobic membrane bioreactor treatment of

695 domestic wastewater at psychrophilic temperatures ranging from $15^{\circ} \mathrm{C}$ to $3^{\circ} \mathrm{C}$. Environ.

696 Sci. Water Res. Technol. 1, 56-64.

697 Sousa, D.Z., Pereira, M.A., Smidt, H., Stams, A.J.M., Alves, M.M., 2007a. Molecular

698 assessment of complex microbial communities degrading long chain fatty acids in

699 methanogenic bioreactors. FEMS Microbiol. Ecol. 60, 252-265. doi:10.1111/j.1574-

$700 \quad 6941.2007 .00291 . x$

701 Sousa, D.Z., Smidt, H., Alves, M.M., Stams, A.J.M., 2009. Ecophysiology of syntrophic

702 communities that degrade saturated and unsaturated long-chain fatty acids. FEMS

$703 \quad$ Microbiol. Ecol. 68, 257-272. doi:10.1111/j.1574-6941.2009.00680.x

704 Sousa, D.Z., Smidt, H., Alves, M.M., Stams, A.J.M., 2007b. Syntrophomonas zehnderi sp. nov.,

705 an anaerobe that degrades long-chain fatty acids in co-culture with Methanobacterium

706 formicicum. Int. J. Syst. Evol. Microbiol. 57, 609-615. doi:10.1099/ijs.0.64734-0

707 Sundberg, C., Al-Soud, W.A., Larsson, M., Alm, E., Yekta, S.S., Svensson, B.H., Sørensen, S.J.,

708 Karlsson, A., 2013. 454 pyrosequencing analyses of bacterial and archaeal richness in 21

709 full-scale biogas digesters. FEMS Microbiol. Ecol. 85, 612-626. doi:10.1111/1574-

$710 \quad 6941.12148$ 
711 Vuono, D.C., Benecke, J., Henkel, J., Navidi, W.C., Cath, T.Y., Munakata-Marr, J., Spear, J.R.,

712 Drewes, J.E., 2015. Disturbance and temporal partitioning of the activated sludge

713 metacommunity. ISME J. 9, 425-435. doi:10.1038/ismej.2014.139

714 Wan, C., Zhou, Q., Fu, G., Li, Y., 2011. Semi-continuous anaerobic co-digestion of thickened

715 waste activated sludge and fat, oil and grease. Waste Manag. 31, 1752-1758.

716 doi:10.1016/j.wasman.2011.03.025

717 Wang, L., Aziz, T.N., de los Reyes, F.L., 2013. Determining the limits of anaerobic co-digestion

718 of thickened waste activated sludge with grease interceptor waste. Water Res. 47, 3835-

719 3844. doi:10.1016/j.watres.2013.04.003

720 Wang, Q., Garrity, G.M., Tiedje, J.M., Cole, J.R., 2007. Naïve Bayesian Classifier for Rapid

721 Assignment of rRNA Sequences into the New Bacterial Taxonomy. Appl. Environ.

$722 \quad$ Microbiol. 73, 5261-5267. doi:10.1128/AEM.00062-07

723 Weng, C., Jeris, J.S., 1976. Biochemical mechanisms in the methane fermentation of glutamic

724 and oleic acids. Water Res. 10, 9-18. doi:10.1016/0043-1354(76)90151-2

725 Werner, J.J., Knights, D., Garcia, M.L., Scalfone, N.B., Smith, S., Yarasheski, K., Cummings,

726 T.A., Beers, A.R., Knight, R., Angenent, L.T., 2011. Bacterial community structures are

727 unique and resilient in full-scale bioenergy systems. Proc. Natl. Acad. Sci. 108, 4158-

728 4163. doi:10.1073/pnas. 1015676108

729 Wu, C., Dong, X., Liu, X., 2007. Syntrophomonas wolfei subsp. methylbutyratica subsp. nov.,

730 and assignment of Syntrophomonas wolfei subsp. saponavida to Syntrophomonas

731 saponavida sp. nov. comb. nov. Syst. Appl. Microbiol. 30, 376-380.

$732 \quad$ doi:10.1016/j.syapm.2006.12.001

733 
734 Yu, Y., Lee, C., Kim, J., Hwang, S., 2005. Group-specific primer and probe sets to detect

735 methanogenic communities using quantitative real-time polymerase chain reaction.

736 Biotechnol. Bioeng. 89, 670-679. doi:10.1002/bit.20347

737 Zengler, K., Richnow, H.H., Rosselló-Mora, R., Michaelis, W., Widdel, F., 1999. Methane

738 formation from long-chain alkanes by anaerobic microorganisms. Nature 401, 266-269.

739 doi: $10.1038 / 45777$

740 Ziels, R.M., Beck, D.A.C., Martí, M., Gough, H.L., Stensel, H.D., Svensson, B.H., 2015.

741 Monitoring the dynamics of syntrophic $\beta$-oxidizing bacteria during anaerobic degradation

742 of oleic acid by quantitative PCR. FEMS Microbiol. Ecol. 91. doi:10.1093/femsec/fiv028

743

744 
Table 1. Total influent volatile solids loading rate (VSLR), FOG VSLR, and the percent of FOG VS in the feed versus time for the FOG codigester. Values in parentheses indicate one standard deviation.

\begin{tabular}{cccc}
\hline Days & $\begin{array}{c}\text { Total VSLR } \\
\text { (g VS/L-day) }\end{array}$ & $\begin{array}{c}\text { FOG VSLR } \\
(\mathrm{g} \text { VS/L-day) }\end{array}$ & $\begin{array}{c}\text { \% FOG in Feed } \\
\text { (VS-basis) }\end{array}$ \\
\hline$-53-0$ & $1.4(0.2)$ & 0 & 0 \\
$1-9$ & $1.9(0.1)$ & 0.25 & 13 \\
$10-37$ & $1.8(0.1)$ & 0.5 & 27 \\
$38-72$ & $2.1(0.1)$ & 0.75 & 36 \\
$73-79$ & $2.4(0.0)$ & 1.0 & 41 \\
$80-93$ & $2.6(0.1)$ & 1.25 & 47 \\
$94-145$ & $2.9(0.1)$ & 1.5 & 52 \\
\hline
\end{tabular}


$\begin{array}{ll}\text { Figure } 4 & \text { FOG Codigester }\end{array}$



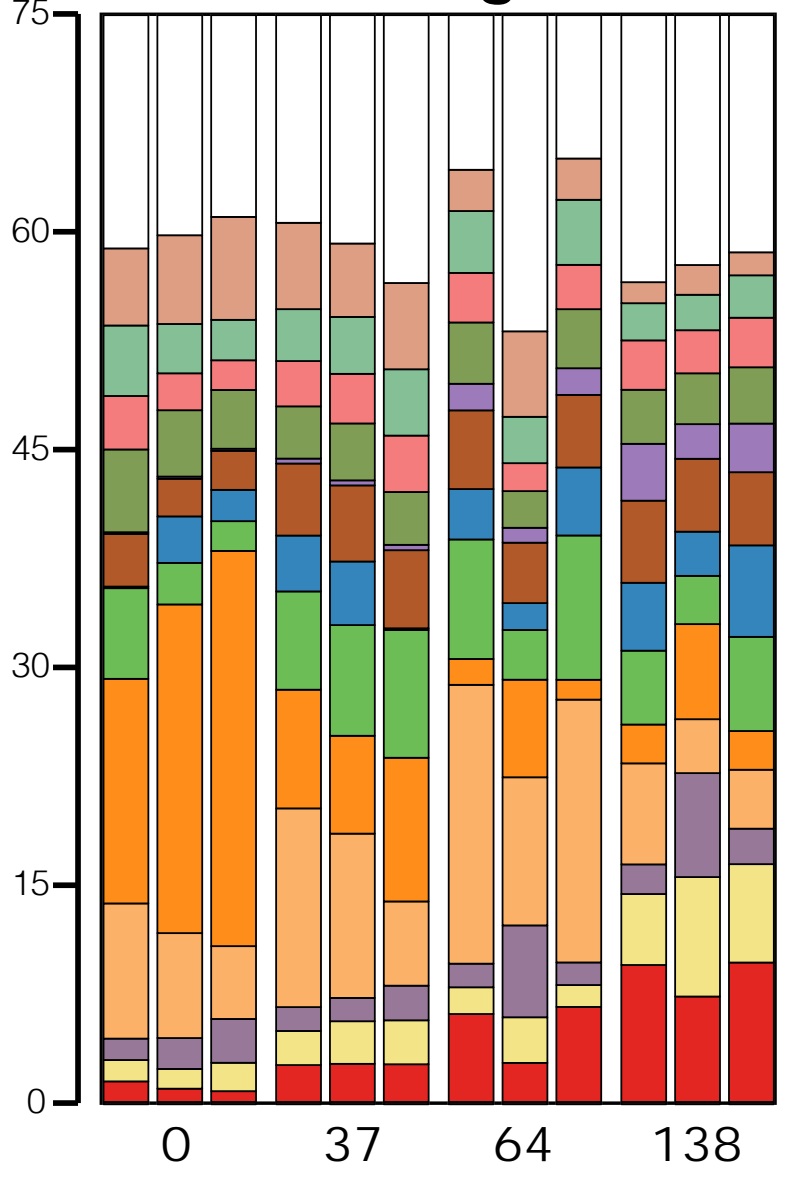

Control

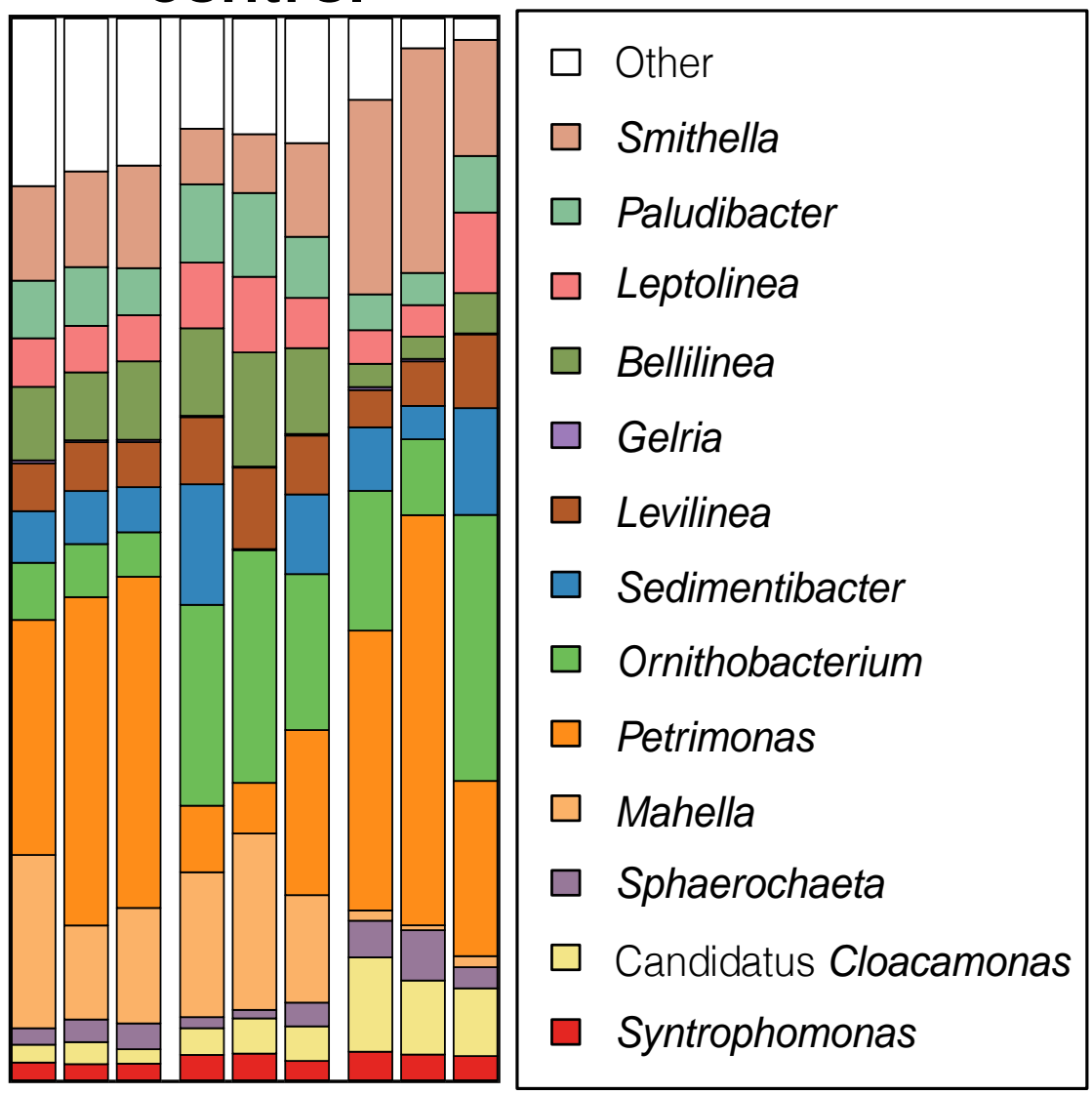

$\square$ Other

- Smithella

- Paludibacter

$\square$ Leptolinea

$\square$ Bellilinea

$\square$ Gelria

$\square$ Levilinea

Sedimentibacter

$\square$ Ornithobacterium

$\square$ Petrimonas

$\square$ Mahella

$\square$ Sphaerochaeta

- Candidatus Cloacamonas Syntrophomonas 


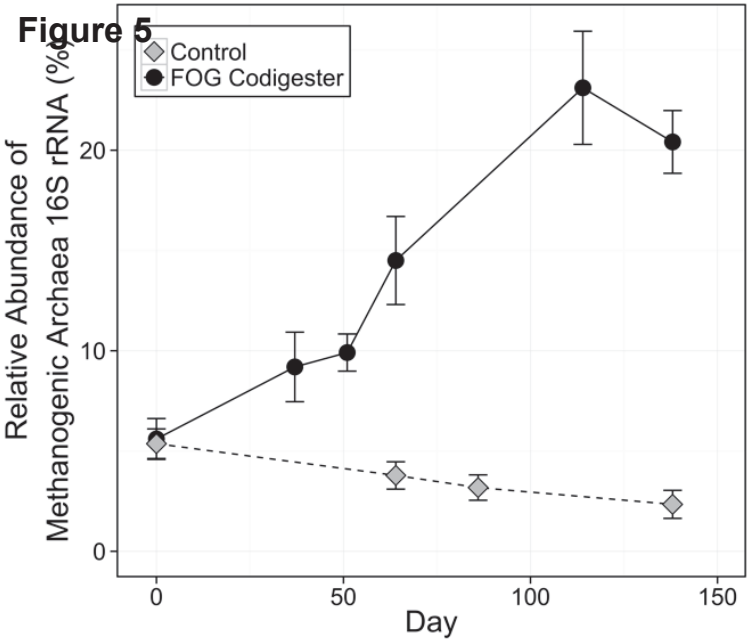


Figure 6

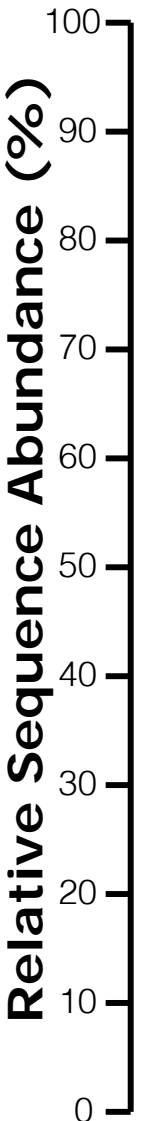

FOG Codigester

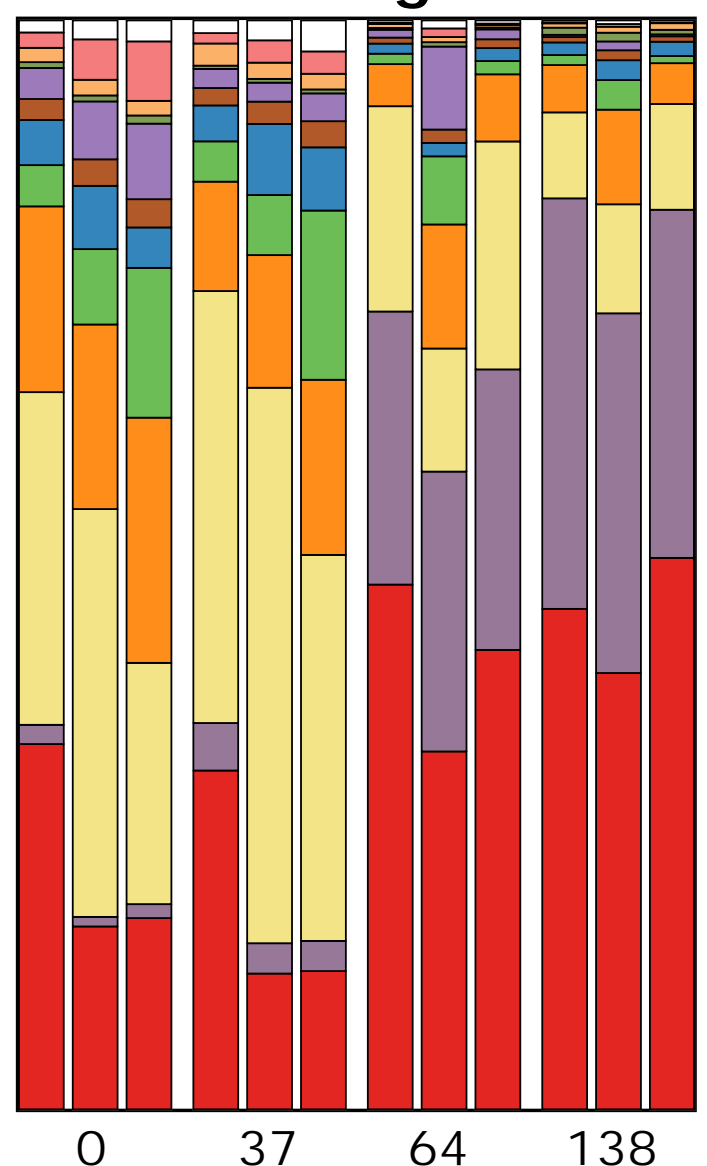

Control

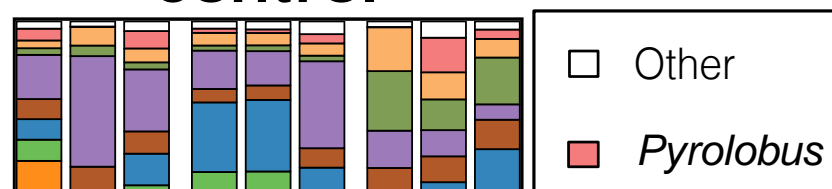

$\square$ Methanobacterium

$\square$ Methanoregula

$\square$ Methanoculleus

$\square$ Methanosphaerula

$\square$ Methanobrevibacter

$\square \quad$ Thermogymnomonas

$\square$ Methanolinea

$\square$ Methanosphaera

$\square$ Methanospirillum

$\square$ Methanosaeta

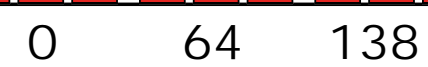

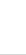


Figure 1: Comparison of the FOG codigester and the control digester performance over experimental period, based on (A) daily volatile solids loading rate, (B) daily methane production, (C) digester $\mathrm{pH}$, and (D) effluent LCFA concentrations. The LCFA concentrations shown in (D) were calculated as the sum of palmitate, stearate, and oleate in the digester effluent solids (error bars represent one standard deviation with $n=4$ ).

Figure 2: Maximum methane production rate in batch assays fed with (A) oleate and (B) acetate, as determined by fitting the Gompertz growth model to observed methane production in triplicate biological replicates. Error bars represent the standard error based on the non-linear regression model fitting $(n=3)$.

Figure 3: Relative fraction of $16 \mathrm{~S}$ rRNA genes of the $\beta$-oxidizing bacterial genera, (A) Syntrophomonas and (B) Syntrophus, within the total Bacteria $16 \mathrm{~S}$ rRNA gene concentration in the FOG codigester and control digester over the experimental period, as determined by qPCR. Error bars represent a standard deviation based on DNA extraction replicates $(n=3)$ and qPCR technical replicates $(n=2)$ for each time point.

Figure 4: Relative sequence fraction of the 13 most abundant genera within the FOG codigester and control digester libraries produced from Illumina MiSeq sequencing of Bacteria 16S rRNA gene amplicons. The triplicate bars shown for each sample day represent replicate DNA extractions. The relative sequence fraction of all other genera were summed, and are shown here as "Other".

Figure 5: Change in the relative fraction of methanogenic Archaea 16S rRNA genes in prokaryotic community of the control digester and FOG codigester. The total methanogenic Archaea 16S rRNA gene concentration was determined as the sum of all methanogen groups targeted in qPCR, and the prokaryotic gene concentration was determined as the sum of methanogenic Archaea and total Bacteria 16S rRNA gene concentrations.

Figure 6: Relative sequence fraction of the 13 most abundant genera within the FOG codigester and control digester libraries produced from Illumina MiSeq sequencing of Archaea 16S rRNA gene amplicons. The triplicate bars shown at each sample day represent replicate DNA extractions. The relative sequence fraction of all other genera were summed, and are shown here as "Other". 
Figure 7: Canonical correspondence analysis (CCA) plots based on (A) Bacteria and (B) Archaea scaled OTU sequence counts in the codigester and control digester samples, constrained by the four highest-scoring environmental gradients: daily methane production, maximum methane production from oleate $\left(q_{\text {max }, \text { oleate }}\right)$, maximum methane production from acetate $\left(q_{\max , a c e t a t e}\right)$, and time (experimental days). The color of the outer circles represents the sample digester source and the color of the inner circles represents the sample collection day. The triplicate samples shown for each sample day are from replicate DNA extractions. The length and direction of each arrow represents the scaling used for that environmental gradient in the CCA model.

Figure 8: Specific effluent LCFA concentration of the FOG codigester versus the FOG to syntroph feed ratio $\left(F: M_{\text {Synt }}\right)$. The exponential trend line was fitted with a non-linear regression method in R v. 3.0.2. Error bars represent one standard deviation. 


\section{fats, oils, and grease}

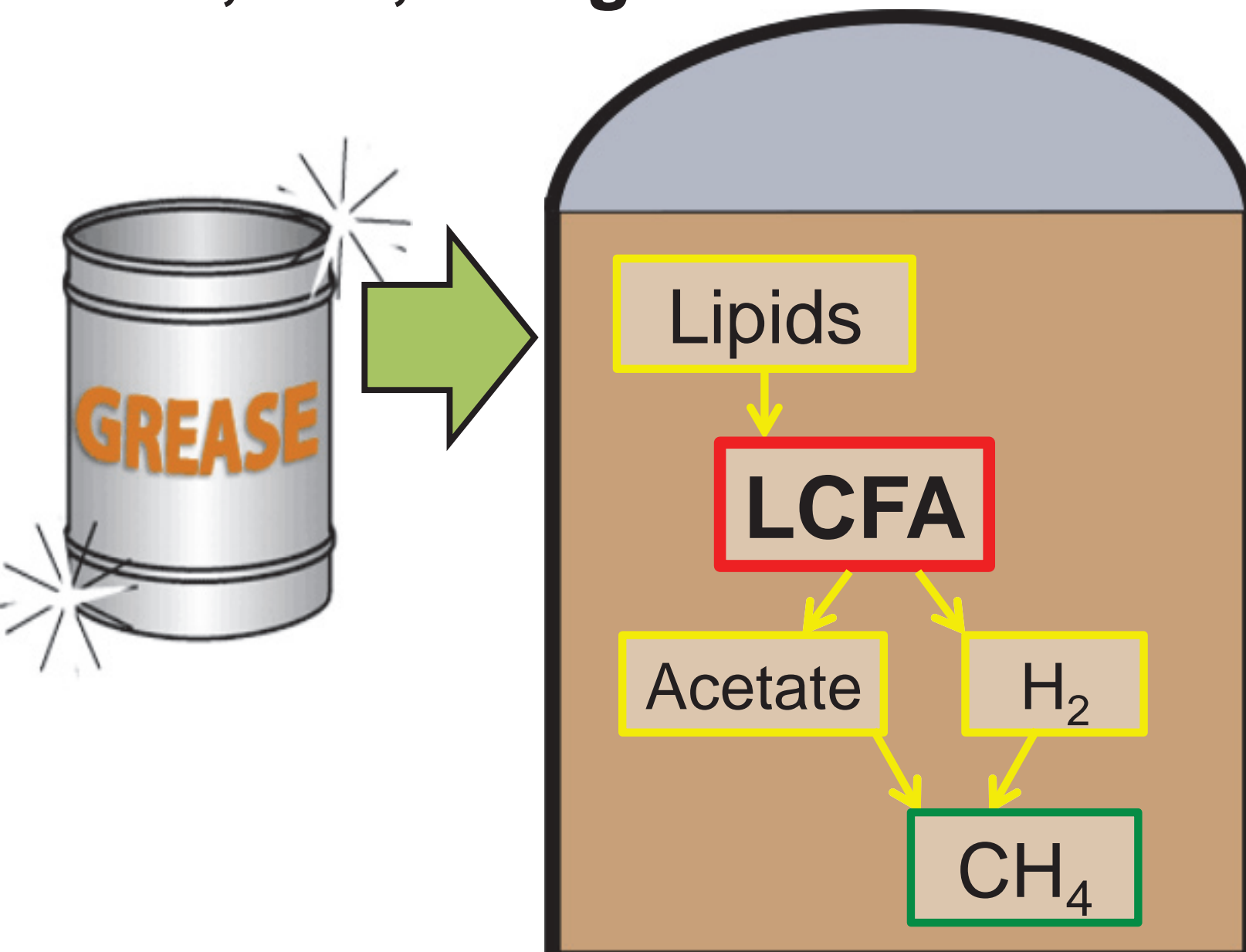

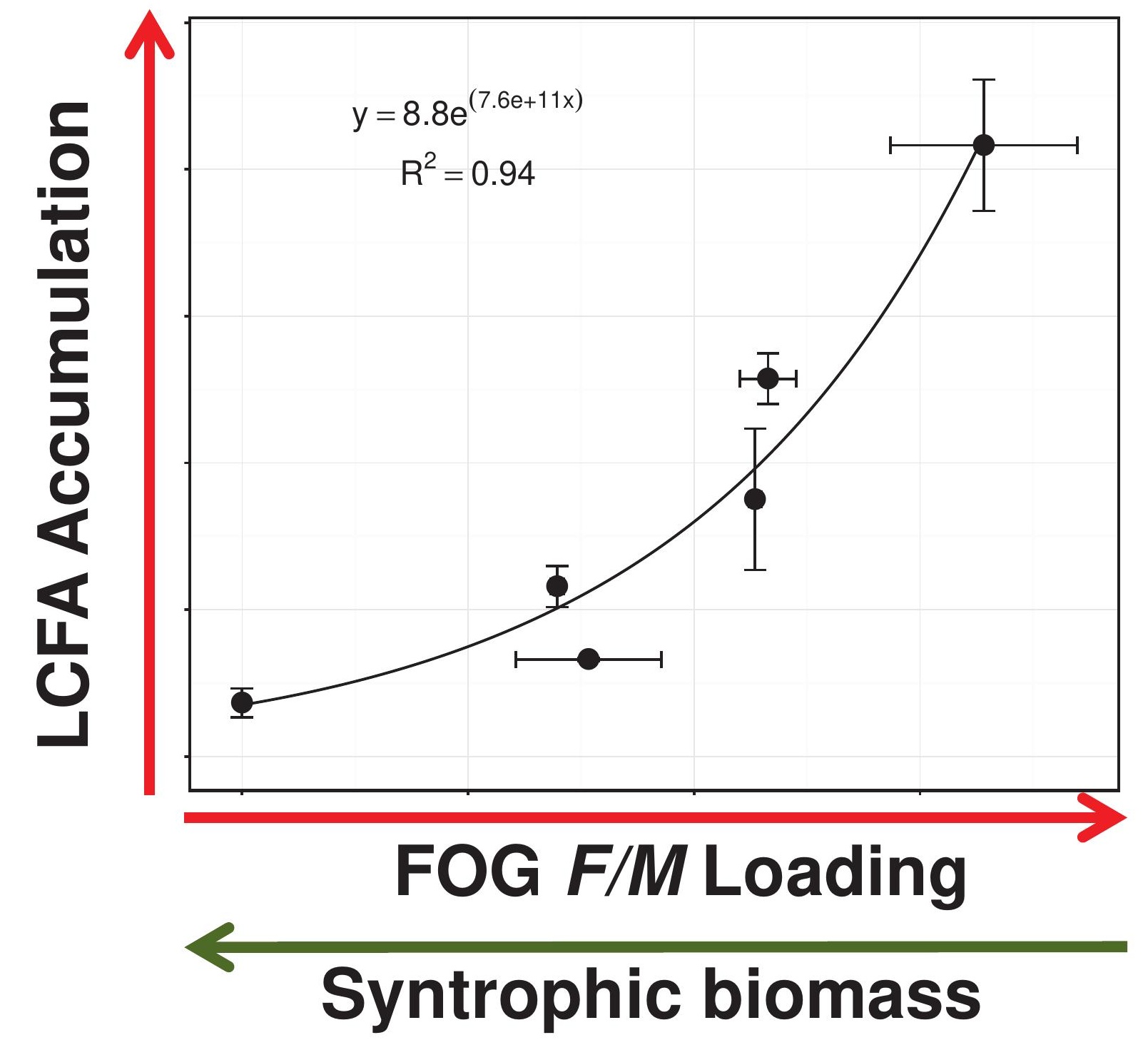


$\begin{array}{ll}\text { Figure } 4 & \text { FOG Codigester }\end{array}$



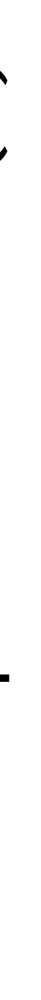
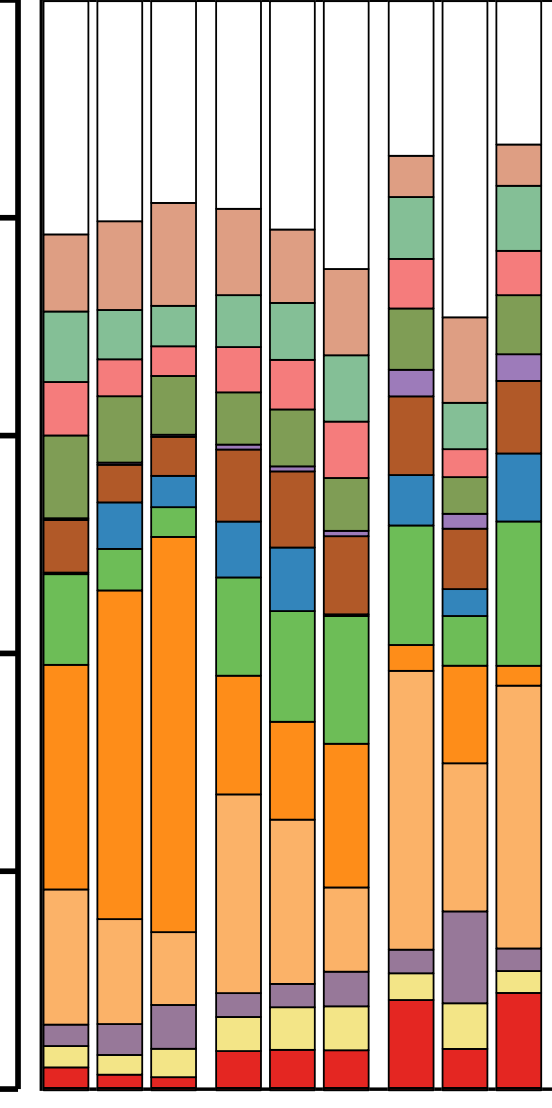

Control

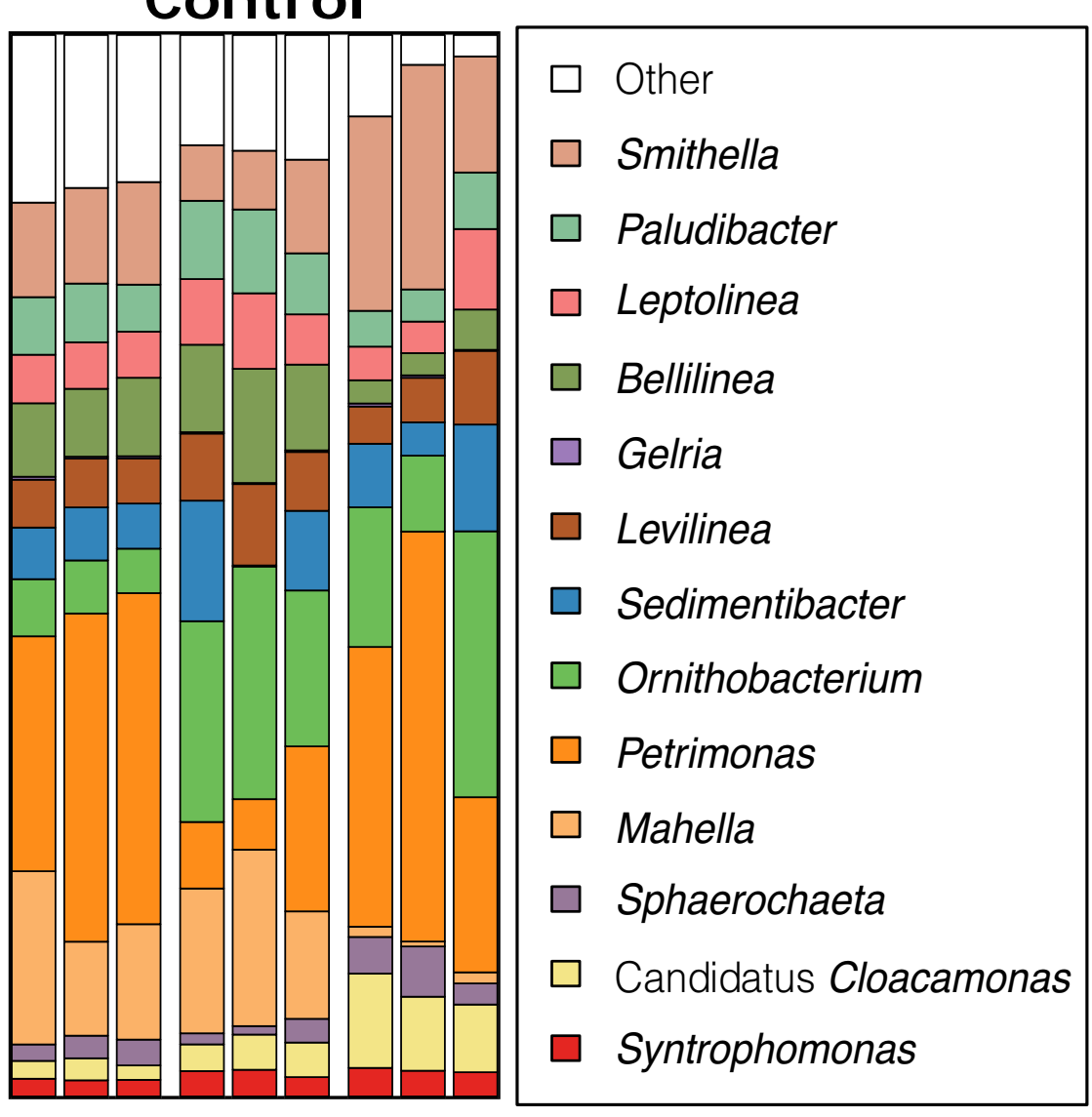

$\square$ Other

Smithella

$\rightarrow \square \quad \square$ Leptolinea

$\square \rightarrow \square-a$ Bellilinea

$\rightarrow \square \square-(-\square$ Gelria

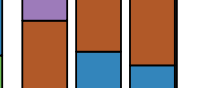
0
37
64
138
Sample Day
0
64
138

$s$

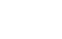




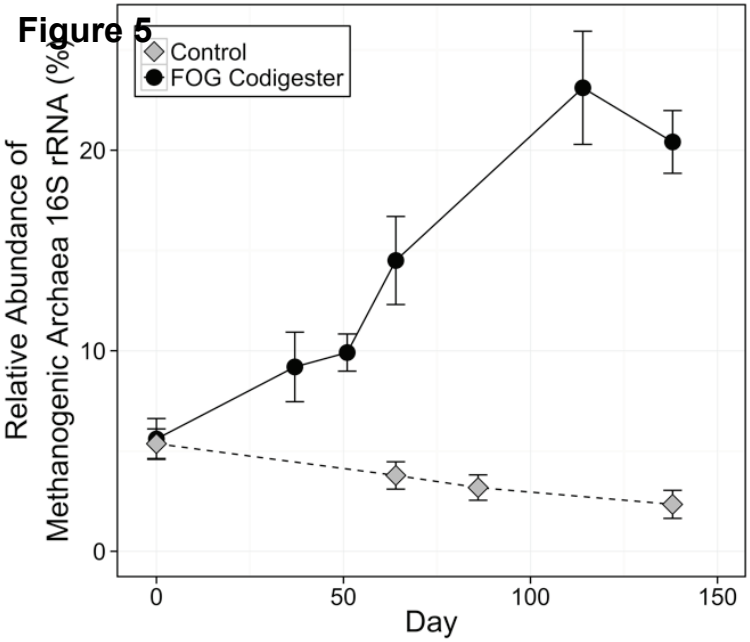


Figure 6

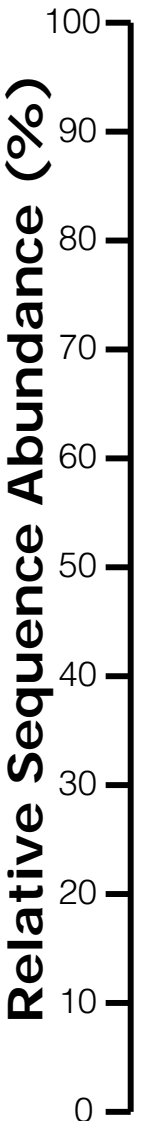

FOG Codigester

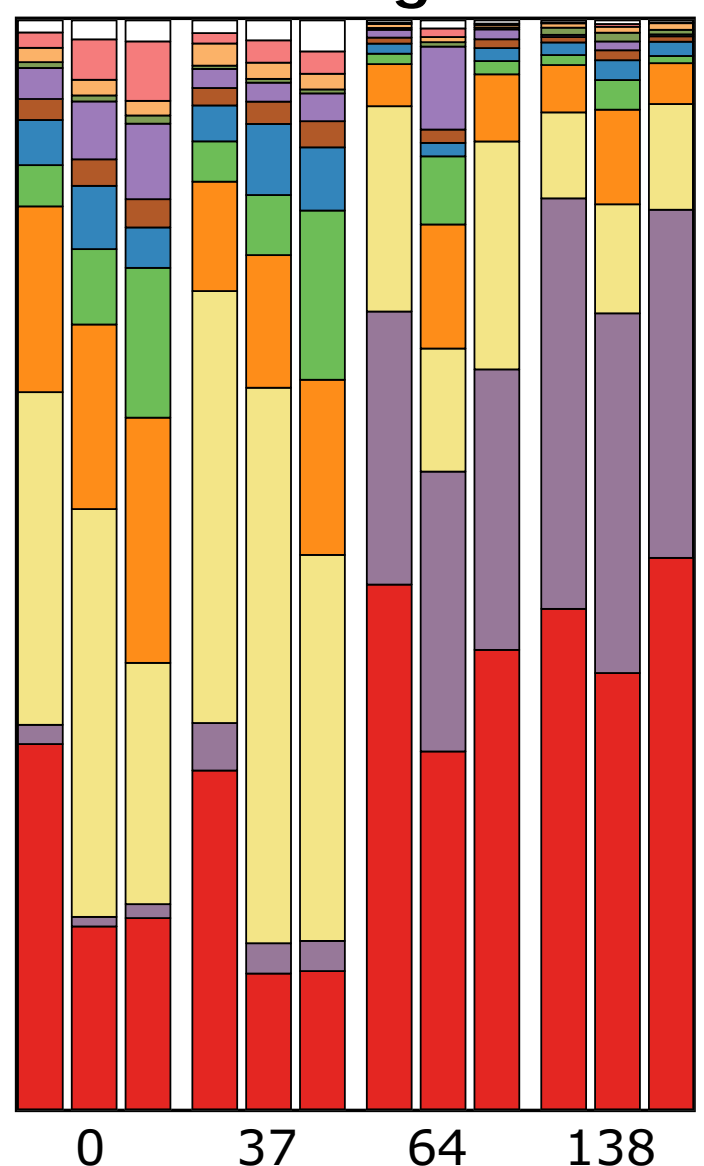

Control

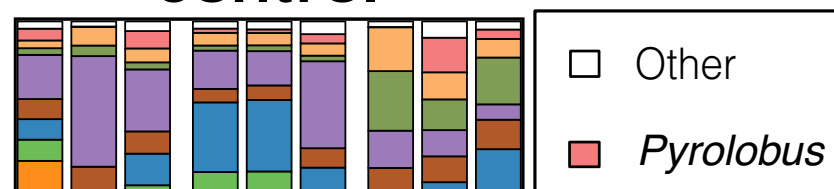

$\square$ Other
$\square$ Pyrolobus
$\square$ Methanobacterium

$\square$ Methanoregula

$\square$ Methanoculleus

$\square$ Methanosphaerula

$\square$ Methanobrevibacter

$\square$ Thermogymnomonas

$\square$ Methanolinea

$\square$ Methanosphaera

$\square$ Methanospirillum

$\square$ Methanosaeta
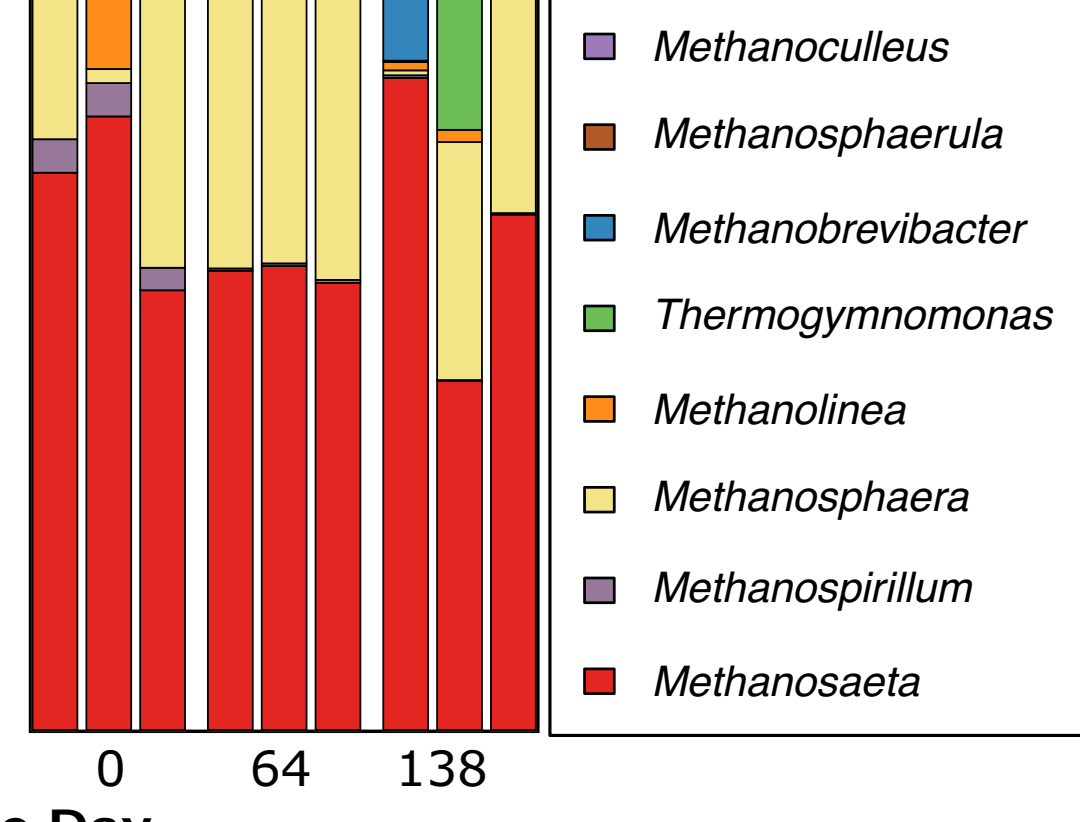

a \\ $\begin{array}{lc}138 & 0 \\ \text { Sample Day }\end{array}$}




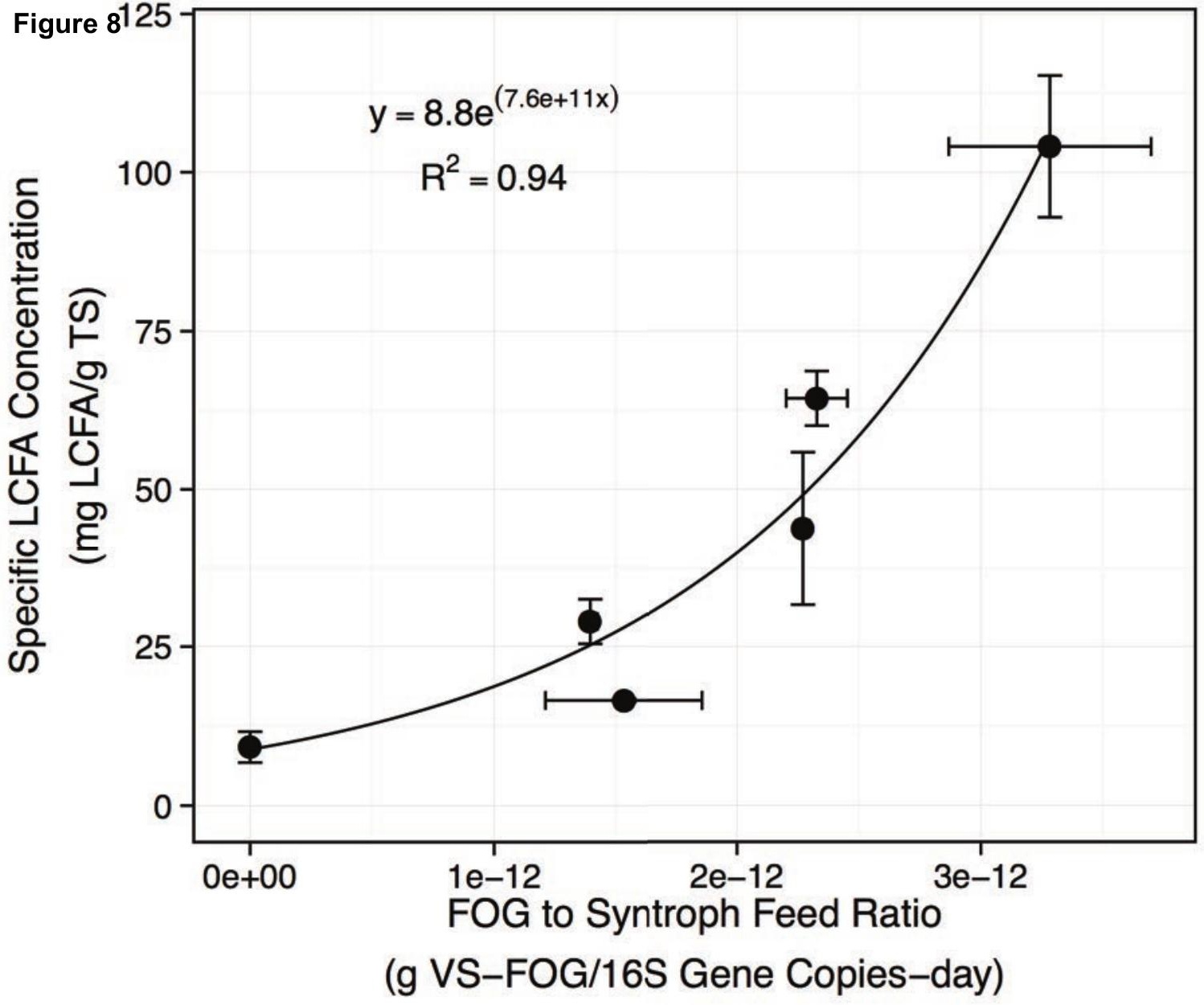




\section{fats, oils, and grease}

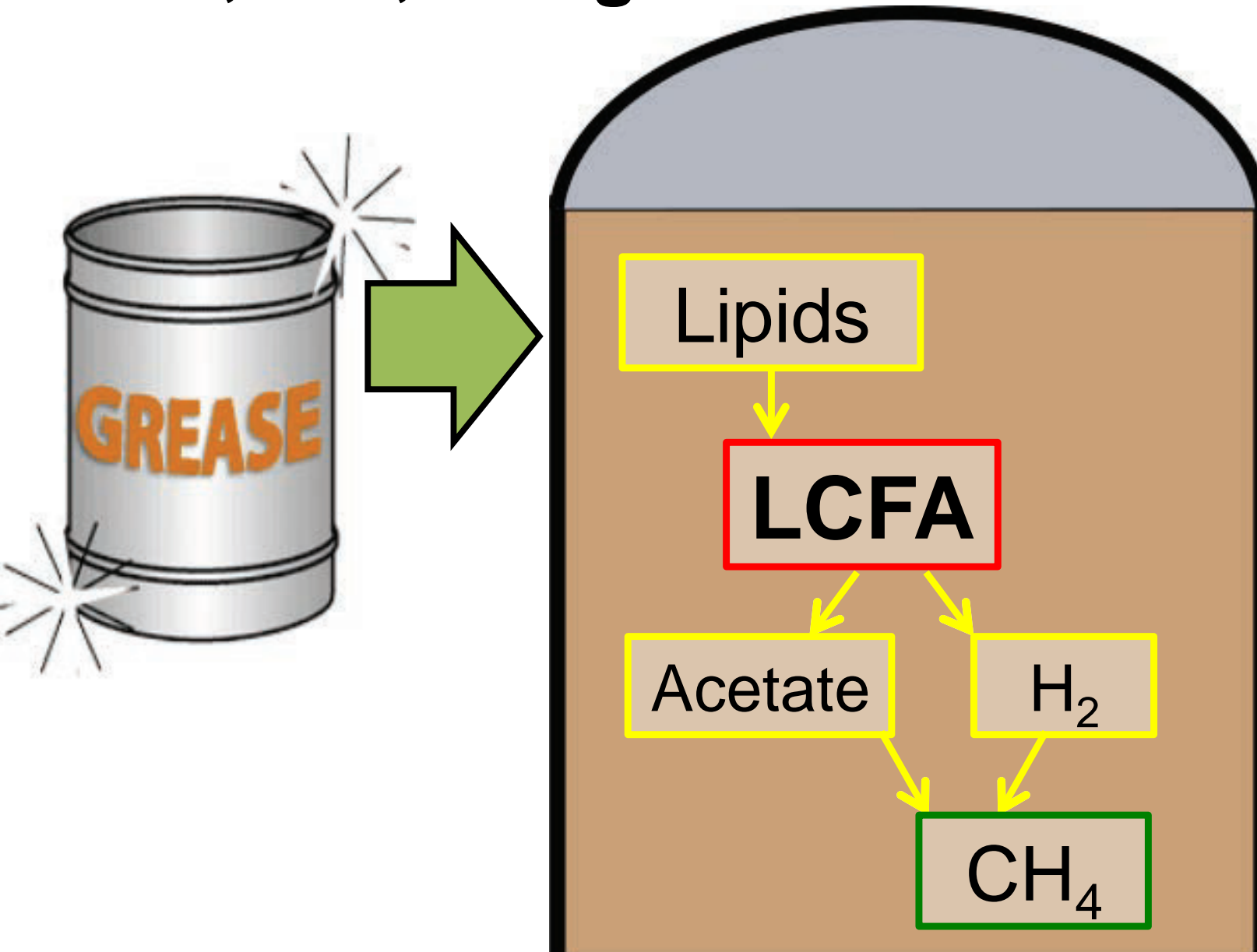

